\title{
NADPH oxidases in Parkinson's disease: a systematic review
}

\author{
Karim Belarbi ${ }^{1}$, Elodie Cuvelier ${ }^{1}$, Alain Destée ${ }^{1}$, Bernard Gressier $^{1}$ and Marie-Christine Chartier-Harlin ${ }^{1,2^{*}}$
}

\begin{abstract}
Parkinson's disease (PD) is a progressive movement neurodegenerative disease associated with a loss of dopaminergic neurons in the substantia nigra of the brain. Oxidative stress, a condition that occurs due to imbalance in oxidant and antioxidant status, is thought to play an important role in dopaminergic neurotoxicity. Nicotinamide adenine dinucleotide phosphate (NADPH) oxidases are multi-subunit enzymatic complexes that generate reactive oxygen species as their primary function. Increased immunoreactivities for the NADPH oxidases catalytic subunits Nox1, Nox2 and Nox4 have been reported in the brain of PD patients. Furthermore, knockout or genetic inactivation of NADPH oxidases exert a neuroprotective effect and reduce detrimental aspects of pathology in experimental models of the disease. However, the connections between NADPH oxidases and the biological processes believed to contribute to neuronal death are not well known. This review provides a comprehensive summary of our current understanding about expression and physiological function of NADPH oxidases in neurons, microglia and astrocytes and their pathophysiological roles in PD. It summarizes the findings supporting the role of both microglial and neuronal NADPH oxidases in cellular disturbances associated with PD such as neuroinflammation, alpha-synuclein accumulation, mitochondrial and synaptic dysfunction or disruption of the autophagy-lysosome system. Furthermore, this review highlights different steps that are essential for NADPH oxidases enzymatic activity and pinpoints major obstacles to overcome for the development of effective NADPH oxidases inhibitors for PD.
\end{abstract}

Keywords: Alpha-synuclein, Microglia, Mitochondria, Neurodegenerative disorders, Oxidative stress, Synaptic plasticity

\section{Background}

Parkinson's disease (PD) is the most prevalent movement disorder in elderly adults. It is characterized by the progressive degeneration of dopaminergic neurons in the substantia nigra and by the pathological accumulation of alpha-synuclein in protein aggregates named Lewy bodies in surviving neurons $[1,2]$. Alpha-synuclein is a protein that is intracellularly localized in presynaptic terminals, where it has been shown to be involved in synaptic vesicle trafficking, synaptic function and plasticity [3]. However, alpha-synuclein can also be released from neurons and this process can be promoted under stress condition and enhanced by alpha-synuclein misfolding and aggregation $[4,5]$. Sustained inflammation, defined by the presence of chronic microglial activation, is also consistently observed in the brain of patients [6].

\footnotetext{
* Correspondence: marie-christine.chartier-harlin@inserm.fr

${ }^{1}$ University Lille, Inserm, CHU Lille, UMR-S 1172 - JPArc - Centre de Recherche Jean-Pierre AUBERT Neurosciences et Cancer, F-59000 Lille, France

2Inserm UMR S-1172 Team "Early stages of Parkinson's Disease", 1 Place de Verdun, 59006 Lille, France
}

These hallmarks are associated with dopamine deficit at the striatum -e.g. the striatal area innervated by the substantia nigra- that is the main factor leading to bradykinesia, resting tremor, rigidity and postural instability. It is generally accepted that these motor symptoms appear only after a substantial proportion of substantia nigra dopaminergic neurons are lost [7] suggesting that the disease has been engaged for years. This raises the possibility of adaptive or compensatory mechanisms in the early phase of this disease, involving synaptic plasticity of the remaining neurons $[8,9]$.

More than $90 \%$ of PD cases are sporadic and attributed to a combination of environment and/or genetic factors. Understanding the function of genes mutated in rare hereditary forms of PD has contributed to a better knowledge of PD pathogenesis. Missense mutations in the gene encoding alpha-synuclein SNCA (synuclein, alpha [non-A4 component of amyloid precursor]) were the first genetic abnormalities to be identified in PD families segregating as an autosomal dominant inherited 
trait [10]. Subsequently $S N C A$ locus triplication and duplication were also shown as a cause of rare familial forms of PD [11-13]. Genetic evidence for a role of alpha-synuclein in sporadic PD emerged from the association between polymorphisms regulating SNCA levels and sporadic PD [14, 15], supporting that alphasynuclein level is instrumental in the most common forms of the disease. Other mechanisms are involved. Mutations in genes encoding proteins of the endosomal/ lysosomal system, vacuolar protein sorting-35 (VPS35), type 5 P-type ATPase ATP13A2, and glucocerebrosidase (GBA1) are also associated with PD [16] and represent a link between autophagy-lysosome function and neurodegeneration. Furthermore, overexpression of leucine-rich repeat kinase 2 (LRRK2), another PD-related protein, causes an increase in autophagosome numbers and lysosomal $\mathrm{pH}$ [17]. Other genes with a recessive PD-related inheritance such as DJ-1, PARKIN, PTEN-induced kinase 1 (PINK1) encode proteins playing an important role in the process of autophagy of mitochondria, known as mitophagy [16]. Mutations in one of these genes lead mitochondria to be morphologically aberrant and bioenergetically incompetent [18]. Although microglia activation and inflammatory changes are generally considered as a consequence of neuronal destruction, genome-wide analysis evidenced that the $H L A-D R$ region [19] and that genes involved in the 'regulation of leucocyte/lymphocyte activity', 'cytokine-mediated signaling' and more generally in the immune system are associated with an increased susceptibility to PD [20, 21]. This raises the possibility that a general pro-inflammatory state could be a primary cause of neuronal loss in some cases or at least increases PD risk as a disease modifier genotype. Thus, the identification of these PD-related genes has led to the proposition that the progressive deterioration of dopaminergic neurons may arise from cellular disturbances produced by misfolding and aggregation of alphasynuclein, mitochondrial dysfunction, disruption of the autophagy-lysosome system, endoplasmic reticulum stress, dysregulation of calcium homeostasis as well as chronic neuroinflammation $[22,23]$. The discovery that environmental factors may be associated with PD promoted the creation of toxin-induced animal models designed to elucidate the mechanisms of neurodegeneration [24, 25]. Some of the most widely used toxins to study PD in animals include 6-hydroxydopamine (6-OHDA), 1-methyl-4-phenyl1,2,3,6-tetrahydropyridine (MPTP) as well as pesticides such as rotenone (an insecticide) and paraquat (an herbicide). These models can present important features associated with the human disease including alpha-synuclein fibrillation, dopaminergic neuronal cell loss, mitochondrial dysfunction as well as oxidative damages (for review, see [26]).

The aforementioned cellular disturbances observed in the genetic and environmental models of PD are all closely linked to oxidative stress [23]. The term oxidative stress describes a redox imbalance between generations of free radicals or other reactive species and antioxidant defenses, and it may be related to changes in microglia activation, protein clearance, mitochondrial function and the autophagy-lysosome system. Oxidative stress has long been hypothesized to be central in sporadic PD pathogenesis. It was already proposed in 1990 that free radicals generated from oxidation reactions inappropriately oxidize macromolecules resulting in cellular dysfunction and, ultimately, in cell death [27]. This hypothesis is supported by several data. First, dopaminergic neurons of the substantia nigra are particularly sensitive to oxidative stress due to their high neuromelanin content, the generation and auto-oxidation of dopamine generate oxygen species. Second, this area is highly demanding in energy and the discovery in the early 1980s of the mechanism of toxicity of MPTP showed that inhibition of mitochondrial complex I activity causes a degeneration of the nigrostriatal neurons and a parkinsonian syndrome in humans, rodents or primates (as reviewed in [28]). Third, studies of postmortem brain tissues demonstrate increased oxidation of proteins [29], lipids [30] and DNA [31] and decreased levels of the antioxidant glutathione [32,33] in the substantia nigra of PD patients. Finally, The substantia nigra contains the highest density of microglia in both human [34] and rodents [35] and their activation may therefore encounter an excessively high level of oxidative stress. Uncertainty about the molecular mechanisms leading to the oxidative stress in sporadic PD remains. A moderate deficit in mitochondrial complex I has been repeatedly evidenced in the substantia nigra of PD patients [36-38]. Furthermore, multiple aforementioned genes in which mutations or polymorphisms increase the risk of PD are linked to mitochondrial function or autophagy. As a consequence, it is considered that accumulation of bioenergetically compromised mitochondria could contribute to reactive oxygen generation in PD. However, other sources of reactive oxygen species in the nervous system could also be involved.

In the present review, we consider the role in PD of enzymatic sources that generate reactive oxygen species as their primary function that are the nicotinamide adenine dinucleotide phosphate (NADPH) oxidases. NADPH oxidases comprise a family of multi-subunit membrane-bound enzymes. Several NADPH oxidases have been evidenced in both neurons and glial cells in the brain where they contribute to a wide range of physiological functions related for example to hostdefense or long-term synaptic plasticity. However, an overproduction of reactive oxygen species by NADPH oxidases could be detrimental. Based on the literature, we discuss how both microglial and neuronal NADPH 
oxidases could contribute to key cellular disturbances in PD such as microglia activation, alpha-synuclein accumulation, mitochondrial and synaptic dysfunction or disruption of the autophagy-lysosome system.

\section{The family of NADPH oxidases}

NADPH oxidases are multi-subunit enzymes that primary catalytic function is the generation of reactive oxygen species. They function as electron transporters, using reduced $\mathrm{NADPH}$ as electron donor and molecular oxygen as electron acceptor to generate superoxide and/or hydrogen peroxide. Reactive oxygen species generation by NADPH oxidases was first discovered in polymorphonuclear neutrophils [39] as the enzyme responsible for the respiratory burst essential to the microbicidal function of these cells [40]. To the phagocytic catalytic subunit Gp91phox, called Nox2 (genomic location Xp21.1-p11.4) in the novel terminology, have been added six additional catalytic subunits of the same family: Nox1 (Xq22.1) [41, 42], Nox3 (6q25.3) [43], Nox4 (11q14.3) [44, 45], Nox5 (15q23) [46] and dual oxidase 1 and 2 (Duox1 15q21.1 and Duox2 15q21.10) [47, 48]. Duox1 and Duox2 are termed dual oxidase because they contain both a NADPH oxidase domain and a peroxidase-like domain. However, according to current knowledge, these two catalytic subunits do not display any peroxidase activity in human [49-51]. They are also named Nox6 and Nox7 according to [52].

All catalytic subunits of the NADPH oxidases family contain a 'NADPH oxidase domain' that is characterized by at least six membrane-spanning alpha-helical domains containing two hemes, a predicted region for flavin adenine dinucleotide (FAD) and a NADPH binding site in the cytosolic C-terminus [53] (Fig. 1). Despite this similar core structure, the NADPH oxidase family members differ in their subunit requirements (Table 1). Some of the NADPH oxidase catalytic subunits require association with other proteins that function as subunits such as p22phox, p40phox, p47phox, and p67phox and necessitate small GTPase Rac1 or Rac2 [54], as listed below. Nox1 requires both p22phox and NoxA1 for activation. The activation of Nox2, that is permanently membrane bound and associated with the p22phox subunit [55], needs the cytosolic subunits p40phox, p47phox, p67phox and the small GTPase Rac1 or Rac2 to migrate to the

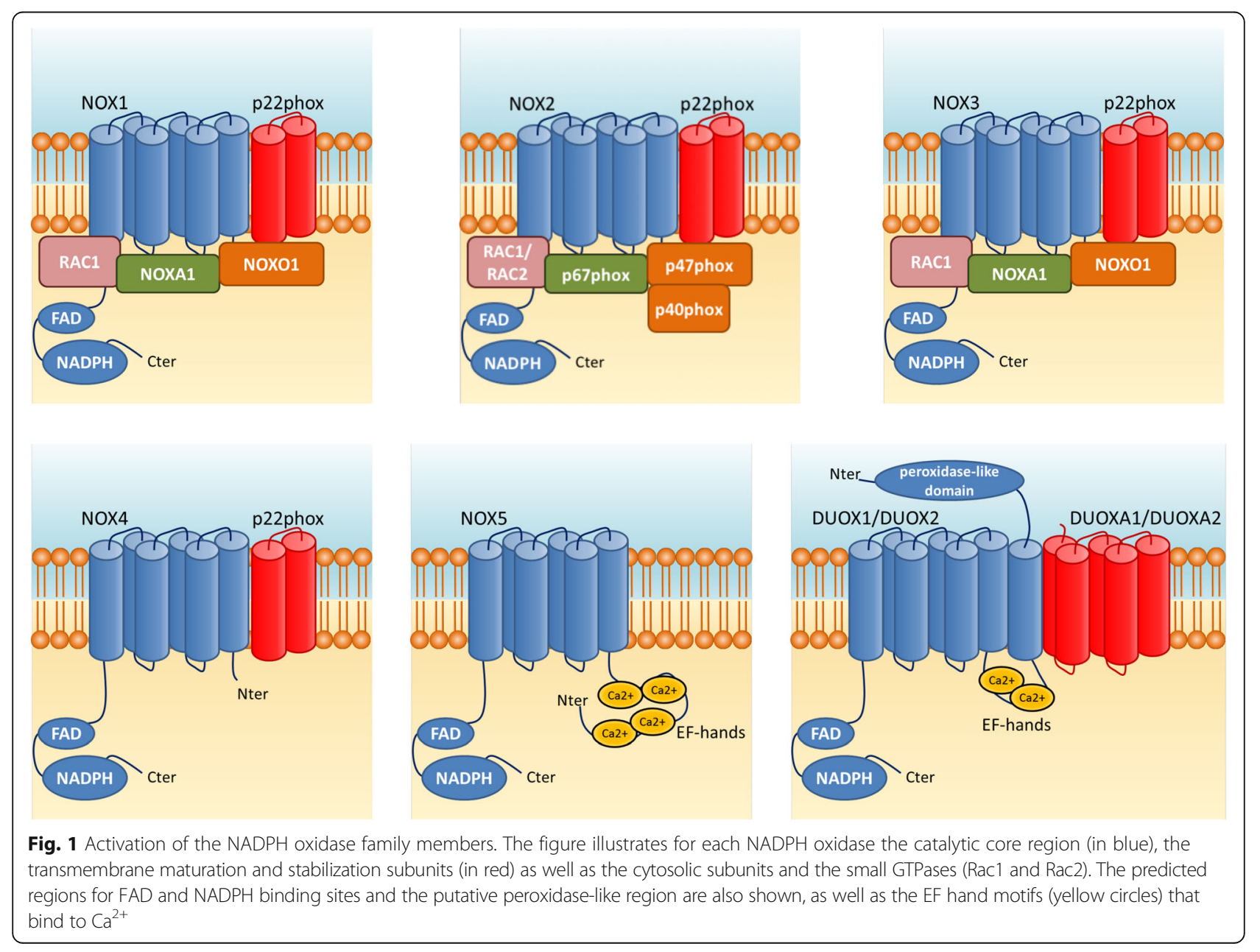


Table 1 Human NADPH oxidases genes, genomic positions and isoforms

\begin{tabular}{|c|c|c|c|c|c|c|}
\hline \multirow{2}{*}{$\begin{array}{l}\text { NADPH oxidase } \\
\text { catalytic subunit } \\
\text { Nox1 }\end{array}$} & \multicolumn{2}{|c|}{$\begin{array}{l}\text { Official Gene symbol and } \\
\text { Full Name HUGOa }\end{array}$} & \multirow{2}{*}{$\begin{array}{l}\text { Other Proposed Aliases }^{\mathrm{b}} \\
\mathrm{MOX} 1 ; \mathrm{NOH} 1 ; \mathrm{NOH}-1 ; \mathrm{GP} 91-2\end{array}$} & \multirow{2}{*}{$\begin{array}{l}\text { Entrez } \\
\text { Gene IDd } \\
27035\end{array}$} & \multirow{2}{*}{$\begin{array}{l}\text { Genomic } \\
\text { location }^{\text {b }}\end{array}$} & \multirow{2}{*}{$\begin{array}{l}\text { mRNA (RefSeq Accession Numbers } \\
\text { GRCh38/hg38 human genome) } \\
\text { NM_007052 (isoform 1) }\end{array}$} \\
\hline & NOXI & NADPH oxidase 1 & & & & \\
\hline & & & & & & NM_013955 (isoform 2) \\
\hline & & & & & & NM_001271815 (isoform 3) \\
\hline Nox2 & $C Y B B$ & $\begin{array}{l}\text { cytochrome b-245 } \\
\text { beta chain }\end{array}$ & $\begin{array}{l}\text { CGD; NOX2; IMD34; AMCBX2; } \\
\text { GP91-1; GP91PHOX; p91-PHOX; } \\
\text { GP91-PHOX }\end{array}$ & 1536 & Xp21.1-p11.4 & NM_000397 $\rightarrow$ NP_000388 \\
\hline Nox3 & NOX3 & NADPH oxidase 3 & het; GP91-3; nmf250 & 50508 & $6 q 25.3$ & NM_015718 $\rightarrow$ NP_056533 \\
\hline \multirow[t]{8}{*}{ Nox4 } & NOX4 & NADPH oxidase 4 & KOX; KOX-1; RENOX & 50507 & $11 q 14.3$ & NM_016931 (isoform a) \\
\hline & & & & & & NM_001143836 (isoform b) \\
\hline & & & & & & NM_001143837 (isoform c) \\
\hline & & & & & & NM_001291926 (isoform d) \\
\hline & & & & & & NM_001291927 (isoform e) \\
\hline & & & & & & NM_001291929 (isoform f) \\
\hline & & & & & & NM_001300995 (isoform g) \\
\hline & & & & & & NR_120406 \\
\hline \multirow[t]{5}{*}{ Nox5 } & NOX5 & NADPH oxidase 5 & NOX5A, NOX5B & 79400 & $15 q 23$ & NM_024505 (isoform 1) \\
\hline & & & & & & NM_001 184779 (isoform 2) \\
\hline & & & & & & NM_001184780 (isoform 3) \\
\hline & & & & & & NR_033671 \\
\hline & & & & & & NR_033672 \\
\hline \multirow[t]{2}{*}{ Duox1 } & DUOX1 & dual oxidase 1 & LNOX1; THOX1; NOXEF1 & 53905 & $15 q 21.1$ & $\begin{array}{l}\text { NM_017434 (dual oxidase } 1 \\
\text { precursor) }\end{array}$ \\
\hline & & & & & & $\begin{array}{l}\text { NM_175940 (dual oxidase } 1 \\
\text { precursor) }\end{array}$ \\
\hline \multirow[t]{4}{*}{ Duox2 } & DUOX2 & dual oxidase 2 & $\begin{array}{l}\text { TDH6; LNOX2; THOX2; NOXEF2; } \\
\text { P138-TOX }\end{array}$ & 50506 & $15 q 21.1$ & $\begin{array}{l}\text { NM_001190392 dual oxidase } \\
2 \text { precursor }\end{array}$ \\
\hline & & & & & & $\begin{array}{l}\text { NM_177610 dual oxidase } 2 \\
\text { precursor }\end{array}$ \\
\hline & & & & & & $\begin{array}{l}\text { NM_213999 dual oxidase } 2 \\
\text { precursor }\end{array}$ \\
\hline & & & & & & $\begin{array}{l}\text { NM_024141 dual oxidase } 2 \\
\text { precursor }\end{array}$ \\
\hline
\end{tabular}

${ }^{a}$ HUGO: http://www.genenames.org/. Accessed January 52017

${ }^{b}$ NCBI Entrez Gene: https://www.ncbi.nlm.nih.gov/gene/. Accessed January 52017

chuman GRCh38/hg38 genome: https://genome.ucsc.edu/. Accessed January 52017

plasma membrane and assemble $[56,57]$. In microglia, the phosphorylation and translocation of p47phox appears as the limiting factor for Nox2 activation [58] and various kinases have been implicated in p47phox phosphorylation. These include protein kinase C (PKC) isoforms [59-62], Akt [63, 64] mitogen-activated protein kinases (MAPK) [65], p21-activated kinase (Pak) [66] and extracellular signal-regulated kinase (ERK)1/2 [67]. Regulation of Nox3 appears to depend of the species and in human it needs activator subunits such as p22phox, NoxO1, NoxA1 and Rac for its activity. Nox4 requires p22phox [68] but does not involve cytosolic subunits. It is constitutively active in reconstituted systems $[44,69]$ and can be regulated in response to cytokines and growth factors such as insulinlike growth factor-I and transforming growth factor- $\beta$ [70-72]. Nox5, Duox1 and Duox2 are activated by an elevation in intracellular $\mathrm{Ca}^{2+}$ and do not appear to require subunits, either membrane-bound or cytosolic $[46,73]$.

The patterns of activation of the different NADPH oxidase family members are summarized in Fig. 1. It should be noted that nearly all catalytic subunit display different transcripts and isoforms, and thus the properties of these different family members are probably more complex, possibly to enable specific and fine regulation processes (Table 1). Thus, the existence of various catalytic $\mathrm{NADPH}$ oxidases with differing activation properties 

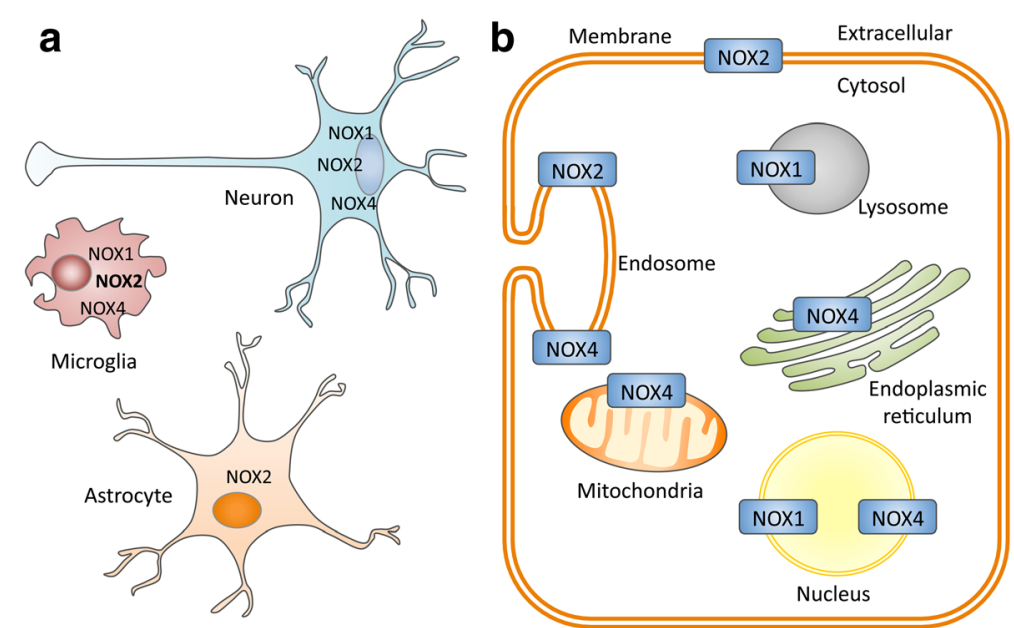

Fig. 2 Cellular and subcellular expression of NADPH oxidase catalytic subunits in the brain. a Schematic diagram showing the reported cellular localization of NADPH oxidase family members in the brain cells. $\mathbf{b}$ Schematic diagram showing the reported subcellular localization of NADPH oxidase family members in a hypothetical cell in the brain

and isoforms, together with various tissue and cell distribution, suggests that NADPH oxidases may have numerous biological functions.

\section{NADPH oxidases in the central nervous system}

Since their identification in polymorphonuclear neutrophils, NADPH oxidases have been evidenced in non-phagocytic cells and in various organs [74], including the brain. A study showed that within total human brain mRNA, Nox2 is predominantly present together with traces of Nox4 and Nox 5 transcripts [43]. Another study detected Nox1, Nox3 and Duox1 in the rat brain tissues [75], further confirming that NADPH oxidases are a plausible generators of reactive oxygen species in the brain.

The distribution of NADPH oxidases in the brain has been studied at the cellular level, in microglia, the resident immune cells of the central nervous system, in neurons and astrocytes (supporting glial cells). In microglia of both humans and rodents, analyses showed that Nox2 is the main NADPH oxidase catalytic subunit present (Fig. 2). Lower levels of Nox1 and Nox4, but not Nox3, have also been documented in microglia at the transcript level [76-81]. In resting microglia and macrophages that can infiltrate the brain under certain pathological conditions, Nox2 localizes to the plasma membrane into cholesterolenriched membrane microdomains (lipid rafts) together with p22phox [77, 82]. Following macrophage/microglia activation, it is internalized by clathrin-coated pits and redistributed to an intracellular compartment consisting of numerous small $(<100 \mathrm{~nm})$ vesicles [83]. Nox1 in microglia appears to localize in intracellular vesicular compartments including lysosomes, and can be recruited to phagosomal membranes [79].
Neurons have been shown to express Nox1 (mRNA; [84]), Nox2 (mRNA and protein; [85, 86]) and Nox4 (mRNA and protein; [87]). Nox4 is predominantly associated with the internal membranes including the endoplasmic reticulum and the endosomes and the mitochondria membrane [68, 88]. In PD patients, Nox1 and Nox4 have been observed in the nucleus of dopaminergic neurons $[89,90]$. While present in most mammals, the Nox 5 gene is absent from rodent genomes [53], therefore preventing the study of the endogenous protein in murine experimental models.

Finally, Nox2 appears to be the predominant NADPH oxidase family member expressed in astrocytes where its expression was reported at both the mRNA and protein level. In line, a significant decrease in reactive oxygen species generation is evidenced in astrocytes from Nox2deficient mice [91, 92]. The cellular and subcellular expression of NADPH oxidases in the brain is summarized in Fig. 2.

The physiological functions of NADPH oxidase enzymes are various, including host defense and inflammation, post-translational processing of proteins, cellular signaling and regulation of gene expression (for review, see $[74,93])$. The majority of publications on the physiological roles of NADPH oxidases in the central nervous system have focused on their participation in the host defense and the removal of debris from the brain. NADPH oxidases have also been shown to regulate neuronal cell fate and function and plasticity, for instance contributing to the induction of neuronal apoptosis in response to serum deprivation [85], to $\mathrm{N}$-methyl-D-aspartate (NMDA) receptor signaling [94] and to long-term potentiation [95]. In the following paragraphs, we provide a thorough review of existing knowledge and information 
relative to the contribution of specific NADPH oxidase family members in microglia and neurons and highlight the main conclusions regarding PD pathogenesis.

\section{NADPH oxidases and microglia activation in PD}

Microglia are the resident mononuclear phagocytes of the central nervous system, belonging to the glial system of non-neuronal cells that support and protect neuronal functions. Microglia comprise $5-20 \%$ of the total glial cell population within the central nervous system parenchyma and most densely populated areas include the substantia nigra [96]. Microglia are not only the first immune sentinels of infection, contributing to both innate and adaptive immune responses locally, but also play intrinsic functions required for normal brain function and neuroprotective effects. Chronic microglia activation is consistently reported in the pathogenesis of PD [97] and can be triggered experimentally by several PD-causing gene products such as alpha-synuclein or DJ-1.

\section{Microglial Nox2 expression is increased in PD and experimental models of PD}

In 2003, Przedborski and coworkers reported that postmortem substantia nigra samples from sporadic PD patients had higher Nox2 (then referred as gp91phox) protein content than samples from control individuals (six PD patients versus three controls; mean duration of disease of $16.8 \pm 2.3$ years) [98]. Nox2 immunostaining localized with the microglial marker CD68, but not with neuromelanin. An increase in microglial Nox2 was also observed in microglia in the ventral midbrain of mice (brain region containing the substantia nigra pars compacta) after repeated intraperitoneal injections of MPTP [98]. In this model, the microglial expression of Nox2 was confirmed by immunostaining co-localization with the marker Macrophage antigen complex-1 (Mac-1) [98] and by ex vivo approaches showing an increase by approximately 3.5 -fold in Nox 2 expression in microglia acutely isolated, compared to saline-treated mice [99]. The MPTP model also show increased p67phox gene expression [98], translocation of the subunit p67phox from the cytosol to the plasma membrane [100], as well as induced p47phox phosphorylation and p47phox-Nox2 complexes in substantia nigra tissues [101], further confirming the activation of the enzyme. A marked increase in Nox2 protein level in reactive microglia was also documented in experimental models of PD based on combined administration of minimally toxic dose of LPS and alpha-synuclein oligomers [102], intraperitoneal injection of paraquat [103] or 6-OHDA [104, 105], on exposure to atmospheric ultrafine particles considered as a potential environmental risk factor for PD [106] as well as with aging and traumatic brain injury known to increase the risk of parkinsonism [107-109].

Taken together, these data strongly suggest that microglia are the predominant Nox2-expressing cells in PD and in several experimental models of PD and that Nox2 activation could contribute to its pathophysiology.

\section{Nox-2 modulates microglial responses and neurotoxicity}

Microglial cells have a wide range of profiles and actions. On one hand, sustained classical microglia activation - consistently detected in the substantia nigra of patients with PD $[6,110-112]$ - could promote the slow degeneration of dopaminergic neurons. This is demonstrated in rodent models based on lipopolysaccharide administration [113, 114]. On the other hand, microglia act as neuroprotective cells through the elimination of endogenous or exogenous substances and participate to the resolution of the inflammatory response [115]. Moreover microglia have high levels of glutathione and glutathione peroxidase, which act to protect them and possibly neurons from toxic levels of $\mathrm{H}_{2} \mathrm{O}_{2}$ [116].

Lipopolysaccharide activates microglia primarily through the pattern recognition receptor Toll-like receptor (TLR) 4 signaling pathway $[113,117,118]$. However, lipopolysaccharide stimulation of Nox 2 activity in microglia mainly occurs through binding of lipopolysaccharide to Mac-1, also named complement receptor (CR) 3 [119, 120]. Mac-1/ CR3 is composed of CD11b (integrin $\alpha \mathrm{M}$ ) and CD18 (integrin $\beta 2$ ) subunits. In Nox2-deficient mice, lipopolysaccharide fails to induce classical microglia activation as evaluated by Iba1 immunoreactive cells morphology, intensified F4/80 staining or induction of tumor necrosis factor (TNF)-alpha expression. Furthermore, lipopolysaccharideinduced loss of dopaminergic neurons is attenuated compared to Nox2+/+ mice [121, 122]. Also, Nox2 deficient microglia do not migrate towards substance $\mathrm{P}$, a proinflammatory neuropeptide with high concentrations in the substantia nigra [123], supporting that Nox2 could be implicated both in the recruitment and the classical activation of microglia.

Nox2 could play a role in the deleterious effects of microglia in PD. For instance studies using cell culture systems revealed that microglia lacking functional Nox2 fail to produce neurotoxicity in response to MPTP [124, 125], paraquat [126] or rotenone in contrast to Nox $2+/+$ microglia [127]. This was corroborated by numerous in vivo studies showing that mice lacking Nox2 are less sensitive to dopaminergic degeneration induced by pesticides. For example, daily subcutaneous injections of MPTP results in a $32 \%$ loss of tyrosine-hydroxylase immunoreactive neurons in Nox $2+/+$ mice compared to a $14 \%$ loss in Nox2-deficient mice [128]. Similar attenuations of neurotoxicity in the Nox2-/- background were observed in mice receiving MPTP injections [98], 
paraquat injections [103] and in mice lesioned with 6OHDA [104, 129]. Consistent with this protection, mice defective in Nox2 show less production of proinflammatory cytokines interleukin-1beta, TNF-alpha or interferon gamma (6-OHDA model; [104]) and less reactive oxygen species production and protein oxidation (MPTP model; [98]). Recently, Zhang and colleagues investigated the mechanisms underlying dopaminergic neurodegeneration using in vivo and in vitro models based on exposure to minimally toxic dose of LPS and alphasynuclein oligomers. In their study, synergistic dopaminergic neurotoxicity - indicated by reduced dopamine uptake capacity, dopaminergic neuronal numbers in the substantia nigra pars compacta and depleted dopaminergic level in striatum - was reduced in Nox2-/- mice compared with Nox2+/+ mice [102]. Furthermore, microglial production of superoxides and reactive oxygen species were robustly reduced in Nox $2-/-$ mice compared to Nox $2+/+$ mice. Thus, both exogenous and endogenous factors involved in PD appear to propagate classical microglia activation and dopaminergic neurodegeneration through activating microglial Nox2.

A role for Nox2 deficiency to promote neuroprotective role of microglia might emerge from the study of Hernandes and colleagues. In this study, Nox2-/- mice were treated with minocycline or saline and received 6OHDA injections. Minocycline is a tetracycline derivative that exerts multiple anti-inflammatory effects, including microglial inhibition. Interestingly, the degeneration of dopaminergic neurons after 6-OHDA injections is greater in Nox2-/- mice that were treated with minocycline compared to Nox2-/- mice treated with vehicle [104]. Minocycline treatment also leads to NF-kappaB activation and increases TNF-alpha release into the substantia nigra of Nox2-/- 6-OHDA lesioned mice [104]. Therefore inhibiting Nox2-/- microglia cells likely increases substantia nigra degeneration and parkinsonism, suggesting a protective role for Nox2-/- microglia.

Although more studies are needed, these data demonstrate that Nox2 adds an essential level of regulation to signaling pathways underlying the inflammatory response. While microglial Nox2 appears to contribute to the chemoattraction, the classical activation and the toxicity towards dopaminergic neurons of microglial cells, inhibiting Nox 2 signaling in microglia could favor their neuroprotective profile and actions in the context of PD.

\section{Alpha-synuclein, DJ-1 and Nox2 in microglia}

Among the factors linked to the etiology of PD, alphasynuclein and DJ-1 have been linked to microglia activation and could modulate NADPH oxidase activity in several ways as described below. Alpha-synuclein has a direct effect on microglial activation in vitro resulting in an overall increase in proinflammatory molecules and oxidative stress [130]. The signaling pathways mediating this process are multiple, and may depend of the structure and/or aggregation state of alpha-synuclein. For instance, alpha-synuclein monomers and fibrils were shown to induce interleukin-1beta release from monocytes via the TLR2 [131] and oligomeric forms of alphasynuclein also specifically activate TLR2 [132]. However, the TLR4 has also been implicated in alpha-synucleininduced inflammation [133]. A role for Mac1 has been proposed and for instance the binding of alphasynuclein to Mac1 has been involved in oxidant release from microglia [134]. Finally, purinergic receptors have been implicated as a direct association between alphasynuclein and the ionotropic P2X7 purinergic receptor leads to Nox2 activation through the phosphoinositide 3-kinases (PI3K) signaling pathway [135].

Both wild-type and A53T mutant alpha-synuclein were shown to activate Nox2 in BV2 microglial cells and in primary cultured microglia, with the A53T form producing quickest and sustained effects in terms of oxidative stress and cellular injuries. Interestingly, the process is partly blocked when BV2 cells are pretreated with LY294002, a strong inhibitor of PI3K [135]. Further supporting that alpha-synuclein promotes microglial Nox2 expression in pathological conditions, neuronal alpha-synuclein levels are elevated after spinal cord ischemic/reperfused injury and when cocultured with injured neurons or supernatants from injured neurons, Nox2 expression, reactive oxygen species generation and TNF-alpha expression are promoted in microglia. In this model, microglia activation is impeded by pretreatment with alpha-synuclein antibody or TLR2 antibodies and Nox2 levels in microglia are reduced by the pharmacological inhibition of MAPK p38 [136]. The comparison of the ability of various alphasynuclein peptides to activate microglia allowed the identification of a specific peptide consisting of amino acids A29-V40 of alpha-synuclein that can directly bind to Nox2 resulting in NADPH oxidase complex activation [137]. When administered to wild-type mice, the A29-V40 peptide increases the expression of MHC-II, a cell surface marker of microglia classical activation [138], as well as the amount of malondialdehyde, one of the products during lipid peroxidation. In contrast, administration of the A29-V40 peptide has no such effects in Nox2-/- mice, suggesting that this alpha-synuclein peptide activates microglia and elicits oxidative stress in vivo in a Nox2dependent manner [137]. Of note, a recent study indicates that the reactive oxygen species originating from activated Nox2 also serve as a direct signal driving microglial directional migration induced by the binding of alphasynuclein to CD11b [139]. Thus, it is likely that several signaling pathways link alpha-synuclein with Nox2 and microglia activation (Fig. 3). Altogether, these findings show an important role for microglia Nox2 in mediating 


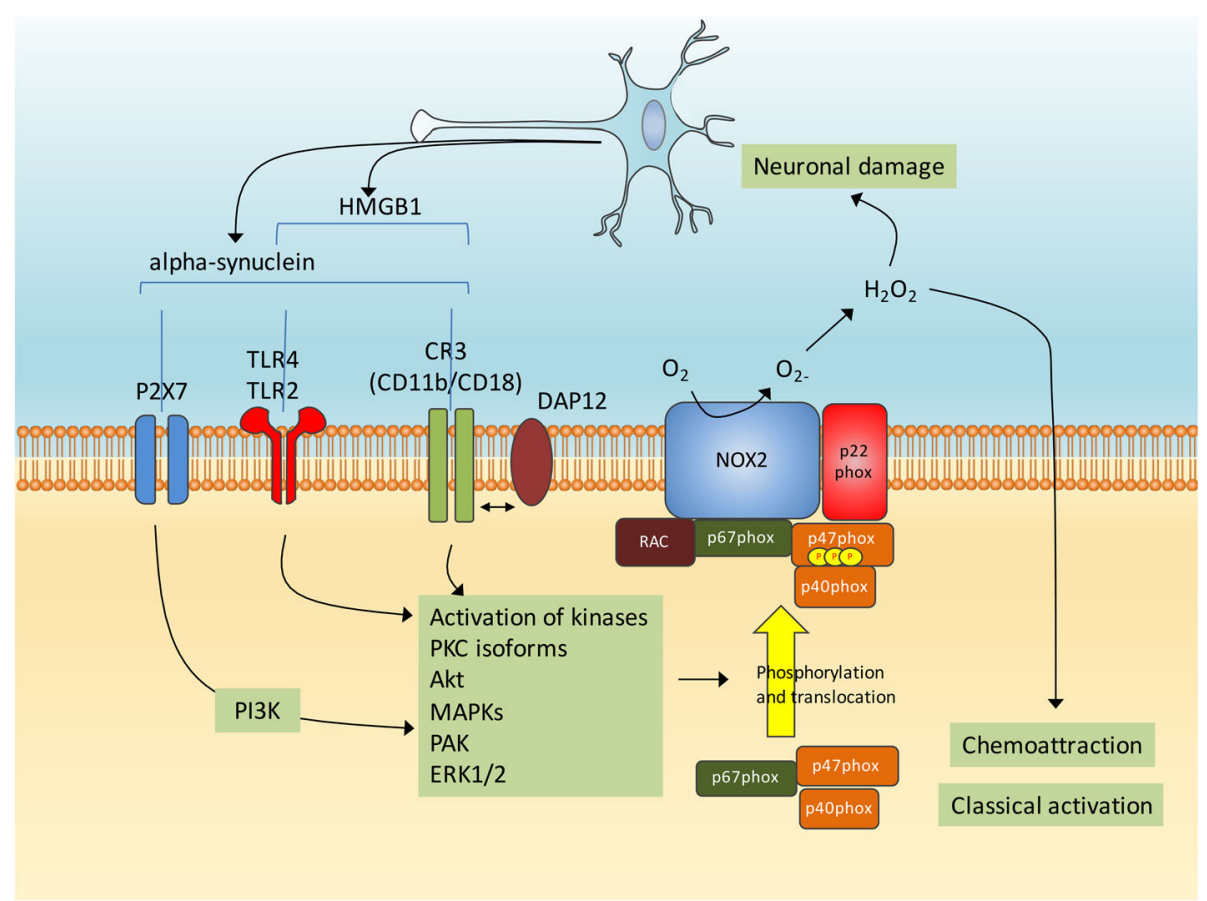

Fig. 3 Alpha-synuclein and microglial Nox2 activation. The activation of microglia by alpha-synuclein can implicate several cell surface receptors such as P2X7, TLR2/4 and CR3 and subsequent activations of several kinases such as PKC, Akt, MAPKs, PAK and ERK1/2. This in turn could promote the phosphorylation and translocation of p47phox and subsequent Nox2 activation. Released oxygen species appear to promote microglia chemoattraction, activation and oxidative stress. Neuronal damage leads to the release of alpha-synuclein and the TLR-agonist high mobility group box protein 1 (HMGB1)

alpha-synuclein elicited microglia chemoattraction, activation and oxidative stress.

DJ-1 is another PD's related gene product that has been suggested to have several possible functions including roles as an oxidative stress sensor, a protein chaperone, a protease, an RNA-binding protein, a transcription regulator, a regulator of mitochondria function and a regulator of autophagy. Recently, Liu and colleagues reported that DJ-1 binds to p47phox and that DJ-1 deficiency blunts TLR signaling and impairs NADPH oxidase-dependent reactive oxygen species production in macrophages. They moreover reported in DJ$1-/$ - versus control mice increased bacterial burdens, reduced local and systemic inflammation, macrophage paralysis and impaired induction of proinflammatory cytokines under the condition of sepsis. Importantly, in vivo administration of DJ-1 restored macrophages and rescued animals from septic death induced by lipopolysaccharide [140]. The study by Amatullah and colleagues also demonstrated the binding of DJ-1 with p47phox. In contrast with the aforementioned study, absence of DJ-1 resulted overall in increased reactive oxygen reactive species production and in increased NADPH oxidase activity, as observed in a mouse model of polymicroglial sepsis (the cecal ligation and puncture model) and in bone marrow-macrophages in response to LPS. The authors then demonstrated that DJ-1-p47phox interaction could disrupt the NADPH oxidase complex assembly and/or facilitate Nox2 ubiquitination and degradation thereby decreasing reactive oxygen species production [141]. Taken together, these two studies evidence that DJ1 binds to p47phox and can modulate NADPH-oxidase function. Future studies are needed to precise the implication of this interaction regarding oxidative stress and inflammation PD and to determine whether PD-related DJ-1 mutations impact on this interaction.

Altogether, these data show that both alphasynuclein and DJ-1 can direct NADPH-oxidases activation in microglia and such signaling could likely interfere with their neurotoxic and neuroprotective effects. The relationship between NADPH-oxidases and other genetic factors associated with $\mathrm{PD}$ will require further investigation. Of note, induction of colitis by dextran sulfate sodium leads to an earlier and severer colitismice paralleled by an increased phosphorylation of LRRK2 in p47phox mutated mice [142]. Addressing whether NADPH-oxidase contribute to changes in the immune response along with LRRK2 in PD will be of prime interest as both factors are expressed in immune cells [143] and appear to be important player in microglial activation and in alpha-synuclein-mediated microglial activation as well [144]. 


\section{Neuronal NADPH oxidases and neurodegeneration in PD}

As discussed in introduction, defects in several cellular processes may push substantia nigra dopaminergic neurons towards cell death. These include oxidative damage, energy failure associated with mitochondrial dysfunction, altered glutamatergic neurotransmission and alterations in protein degradation efficacy. The finding that NADPH oxidases localize to specific subcellular organelles in neurons, such as the nucleus, the mitochondria and pre-synaptic sites [145-148] has raised the possibility that they could contribute to these defects, with implications for the development of neuroprotective therapies.

\section{NADPH oxidases, oxidative damage and alpha-synuclein accumulation in neurons}

The presence of oxidative damage to the content of dopaminergic neurons has been consistently reported in the substantia nigra of PD patients. Suggesting that NADPH oxidases could play a role in these damages, a confocal microscopy imaging study evidenced Nox1 in the nucleus of dopaminergic neurons in the substantia nigra of postmortem brains of four PD patients while no signal was detected in those from control individuals [89]. Nox1 expression is also increased in the substantia nigra dopaminergic neurons in mice or rats in response to intraperitoneal injections of paraquat $[149,150]$ or striatal stereotaxic injection of 6OHDA [89]. In these models, rise in Nox1 expression is associated with an increase in total and proteinase- $\mathrm{K}$ resistant alpha-synuclein levels, as well as with lipid peroxidation (paraquat model; [150]) and immunoreactivity for the DNA oxidative stress marker, 8-oxo-dG (6-OHDA model; [89]). Nox1 knockdown or Rac1 inhibition achieved by stereotaxic delivery of adeno-associated virus serotype 2 (AAV2) particles into the rat substantia nigra significantly reduces 6-OHDA-elicited immunostaining with 8-oxo-dG and dopaminergic neuronal loss [89]. The selective knockdown of Nox1 in the substantia nigra also largely attenuates the paraquatmediated increase of total and proteinase K-resistant alpha-synuclein, oligomer-specific A11 immunoreactivity, oxidative stress and dopaminergic neuronal loss [150]. The Nox1/Rac1 complex was further analyzed in N27 rat dopaminergic cells in which (i) Nox1 tagged with EGFP translocates into the nucleus following 6-OHDA or rotenone treatments and (ii) Nox1 and GTP-bound activated Rac1 were detected by immunoprecipitation of nuclear extracts after a $24 \mathrm{~h}$ treatment with 6-OHDA [89, 151]. Therefore Nox1 translocation to the nucleus likely promotes subsequent Nox1/Rac1-derived superoxide generation responsible for oxidative damages to the neuron and this is associated with increased detrimental alpha-synuclein levels.
More recently, Nox4 immunoreactivity was noted in the nucleus of dopaminergic neurons in PD patients at Braak stage 6 [90], a stage with widespread alphasynuclein accumulation [152]. Very interestingly, when looking at the first-affected nigral subregion nigrosome 1 , the authors evidenced that the nuclear expression of Nox4 increases stepwise from age-matched controls $(n=7)$ to asymptomatic $(n=3)$ to clinically-confirmed PD patients $(n=5)$. Besides being correlated with negative clinical output, the elevated nuclear expression of Nox4 is also associated with oxidative damage to DNA, caspase-3-mediated cell loss and increased distribution of the angiotensin II type 1 (AT1) receptor in the nucleus. Because the activation of the AT1 receptor stimulates NADPH oxidase activity [153, 154] and because AT1 receptor increases with age and in response to 6OHDA treatment [155], the authors propose that angiotensin II/AT1/Nox4 axis-mediated oxidative stress could contribute to damages in neurons in PD [90].

\section{Cross talk between mitochondria and NADPH oxidases in neurodegeneration}

The regulation and maintenance of brain function requires high amount of energy, consuming 20\% of total body energy. Neurons depend primarily in oxidative phosphorylation to meet their energy demands, while glucose metabolism is directed towards the pentose phosphate pathway to generate NADPH. Mitochondrial dysfunction in PD is likely to contribute to energy failure and to the excess of reactive oxygen species and subsequent oxidative damages. Mitochondria and NADPH oxidases are both major sources of superoxide induction and several lines of evidence suggest that they might be considered along in PD. A first argument is that mitochondria can control the transcriptional activation of Nox1 as demonstrated in osteocarcinoma cells. In this model the inactivation of mitochondrial genes leads to the down-regulation of Nox1 expression. Conversely, increasing mitochondrial superoxide levels by exposing the cells to inhibitors of electron transport chain such as rotenone or antimycin increases the expression of Nox1 [147]. A molecular signaling link between mitochondria and Nox1 was further investigated for its contribution to superoxide production and apoptosis induced by serum withdrawal in human $293 \mathrm{~T}$ cells [156]. In this model serum withdrawal promotes the production of reactive oxygen species by stimulating both the mitochondria and Nox1. Mitochondria respond to serum deprivation within a few minutes. The mitochondria-generated reactive oxygen species stimulate PI3K that in turn induces the translocation of Rac1 to membrane fractions and the Rac1/Nox1 interaction, leading to sustained accumulation of reactive oxygen species [156]. Serum withdrawal-treated cells eventually loose their viability, 
which is prevented by blocking either the mitochondriadependent induction of reactive oxygen species using rotenone or potassium cyanide or the PI3K/Rac1/Nox1 pathway using dominant negative mutants or small interfering RNAs [156]. Taken together, these data provide great evidence of a signaling link between the mitochondria and Nox1, which could be crucial for the sustained accumulation of reactive oxygen species and cell death processes in PD.

PINK1, which is linked to autosomal recessive familial $\mathrm{PD}$, is a mitochondria-targeted serine/threonine kinase. It is well established that PINK1 protects neurons from oxidative stress [157] and in particular, loss of PINK1 function causes dysregulation of mitochondrial calcium handling, resulting in mitochondrial calcium overload which stimulates reactive oxygen species production. Of interest, Gandhi and coworkers demonstrated that reduction of NOX2 expression in PINK1 knockdown neuroblastoma cells significantly attenuates reactive oxygen species production [158], therefore evidencing a new signaling pathway at the crossroad between mitochondrial stress, oxidative stress and NADPH-oxidases.

More recently Nox4 was also directly associated to mitochondria as evidenced by confocal microscopy imaging showing its colocalization with the mitochondrial dye Mitotraker both in mice and in a murine catecholaminergic cells [88]. As investigated in this study, the expression level of Nox4 increases following angiotensin II exposure and knockdown of Nox4 achieved by adenoviral-encoded small interfering RNA significantly attenuates the angiotensin IIinduced increase in mitochondrial-localized superoxide production [88]. Therefore it is likely that Nox4 contributes significantly to superoxide production at the mitochondria in response to angiotensin. Although more studies are needed, one can hypothesize that NADPH oxidases activation at the mitochondria could interact with elements of the electron transport chain within the mitochondria, thus indirectly initiating the production of mitochondrial superoxide $[159,160]$.

In conclusion, a cross talk between mitochondria and $\mathrm{NADPH}$ oxidases may represent a feed-forward vicious cycle of reactive oxygen species production that could contribute to oxidative damages and neurodegeneration in PD. NADPH oxidases-targeted antioxidants might break this vicious cycle, reducing NADPH-oxidase and limiting reactive oxygen species production by mitochondria.

\section{NADPH oxidases, synaptic signaling and excitotoxicity}

Neurons utilize most of their energy at the synapse and an impairment of the ability of neurons to undergo synaptic plasticity is key in several theories explaining the onset and the progression of PD [161]. Dopaminergic denervation causes a profound network rearrangement, with the appearance of distinct forms of aberrant synaptic plasticity. Synaptic alterations in PD are also associated with abnormal expression or function of the NMDA receptor, a glutamate receptor and ion channel protein found in nerve cells [162]. Reactive oxygen species are required for NMDA receptor-dependent activation of ERK and long term potentiation [163], both of them being implicated in PD [164]. A specific role for NADPH oxidases at the synapse was initially suggested by Tejada-Simon and colleagues who reported that Nox2, p22phox, p40phox, p47phox, p67phox, and Rac are enriched in synaptoneurosome preparations from mouse hippocampal homogenates. Dual immunofluorescent labeling also show that 67phox or Nox2 colocalize with synaptophysin and synaptotagmin, respectively, confirming their localization at pre-synaptic sites [145]. Isolated synaptosomes have been shown to exhibit NADPH-dependent oxygen consumption and quantitative production of superoxide radicals and these are partially inhibited by the Nox2 inhibitor apocynin [165]. This production appears to be significant as NADPH oxidases rather than mitochondria are identified as the major reactive oxygen species source in isolated synaptosomes from mice, as assayed using spin trapping electron paramagnetic resonance spectroscopy [166]. Taken together, these studies clearly demonstrate the localization of functional NADPH oxidases at the synapse of neurons, making of NADPH oxidases prominent candidates as a source for reactive oxygen species for the control of synaptic neurotransmission.

In 2005, Kishida and colleagues reported that pharmacological inhibition of the NADPH oxidases using diphenylene iodonium or the lack of the p47phox subunit inhibit NMDA receptor-dependent ERK activation in hippocampal slices of mice [94], suggesting a direct role for NADPH oxidases in this signaling pathway. In line, pharmacological inhibition of NADPH-oxidases by diphenylene iodonium or apocynin or knockdown of Nox 2 or p47phox in mice block NMDA receptor-dependent early-phase long-term potentiation in the hippocampus, leaving the basal synaptic transmission intact [95]. Corroborating these results, the rapid increase in superoxide production induced by NMDA receptor activation is blocked by the Nox 2 inhibitor apocynin and in neurons lacking the p47phox subunit, both in cellulo and in vivo [167]. Therefore, Nox2 appears as the primary source of NMDA-induced superoxide production in neurons, being critical for NMDA receptor-related synaptic plasticity. Although these data were obtained in the hippocampus, mice lacking Nox 2 present deficits not only in memory formation but also in the rotating rod and open field tests, suggesting a role for NADPH oxidases in synaptic function in several brain areas [95]. Finally, a role for Nox2 has been evidenced in the release of glutamate and dopamine after the administration of the NMDA receptor antagonist ketamine in mice [168]. Future research is needed to explore whether NADPH oxidases deregulations 
could control NMDA receptor-dependent glutamate and dopamine release in the context of PD.

While NMDA receptor is critical for synaptic plasticity, its sustained activation leads to extensive superoxide production promoting neuronal death [169]. As such, the finding that NMDA receptor stimulation triggers NADPH oxidases activation also provides a mechanistic link between oxidative stress and excitotoxicity. Of interest, PI3K is essential for NMDA receptordependent activation of Nox2; for example the PI3K inhibitor wortmannin reduces NMDA-induced Nox2 activation and cell death in primary neuronal cultures [170]. Perturbations in the PI3K/Akt pathway have been reported in PD patients $[171,172]$ and, as such, may either increase or decrease Nox2 superoxide production thereby impacting synaptic plasticity, the release of neurotransmitters and excitotoxicity in PD. This suggests that deregulation in NADPH oxidases expression, localization or activation could directly contribute to synaptic defects and excitotoxicity in PD.

\section{NADPH oxidases and the autophagy-lysosome system}

Autophagy is a dynamic cellular pathway involved in the degradation of misfolded proteins and other cellular constituents. Impairment of the autophagic flux has been evidenced in PD and could promote the accumulation of compromised mitochondria and alpha-synuclein [23]. Several publications reported that exposure to rotenone can impair the autophagic flux, resulting in cytosolic accumulation of the autophagosomal membrane form of microtubule-associated protein 1 light chain 3 (LC3) [173], increased p62 levels [174] and aberrant accumulation of alpha-synuclein [175]. This rotenone's impact on autophagy likely occurs through the PI3K/Akt/mTOR signaling pathway [173, 176]. To determine whether rotenoneinduced autophagy was Nox2 dependent, Pal and colleagues used the human neuroblastoma SH-SY5Y cell line. They observed that short exposure to rotenone $(0.5 \mu \mathrm{M}$; $6 \mathrm{~h}$ ) results in a $\sim 2$-fold increase in reactive oxygen species generation, impairs autophagic flux and promotes protein accumulation. Pre-incubation with the Nox2 docking sequence (Nox2ds)-tat significantly attenuates the levels of LC3 and p62 proteins, indicating that the effect on autophagy is mediated by Nox-2 dependent reactive oxygen species. When SH-SY5Y dopaminergic cells are exposed to higher doses of rotenone (10 $\mu \mathrm{M} ; 24 \mathrm{~h})$, a $\sim 3.5$ increase in reactive oxygen species generation is observed compared to untreated cells. Nox2-ds abolish Nox2-generated reactive oxygen species generation (measured using the Nox2specific redox sensor p47-roGFP) while total intracellular reactive oxygen species (measured using DCF-DA) is partially, but not completely, inhibited [177]. This suggests that $10 \mu \mathrm{M}$ rotenone for $24 \mathrm{~h}$ stimulates reactive oxygen species generation not only through Nox2, but also possibly from mitochondria. Importantly, preincubation with Nox2-ds partially attenuates LC3 and p62 protein levels and protects against rotenone-dependent upregulation in apoptotic signaling [177]. These data highlight a novel mechanism by which Nox2-dependent oxidative stress could promote the pathogenesis of PD. Noteworthy, Nox4 was also found to promote autophagy and survival in cancer cells [178] and in cardiomyocytes in response to nutrient deprivation and ischemia [179], while no studies have been performed yet in the neuronal context. Thus, this emerging evidence indicates the importance of NADPH oxidases in the regulation of autophagy. Future studies are warranted to delineate the association between NADPH oxidases-dependent impaired autophagy, mitochondria dysfunction and cell death in PD.

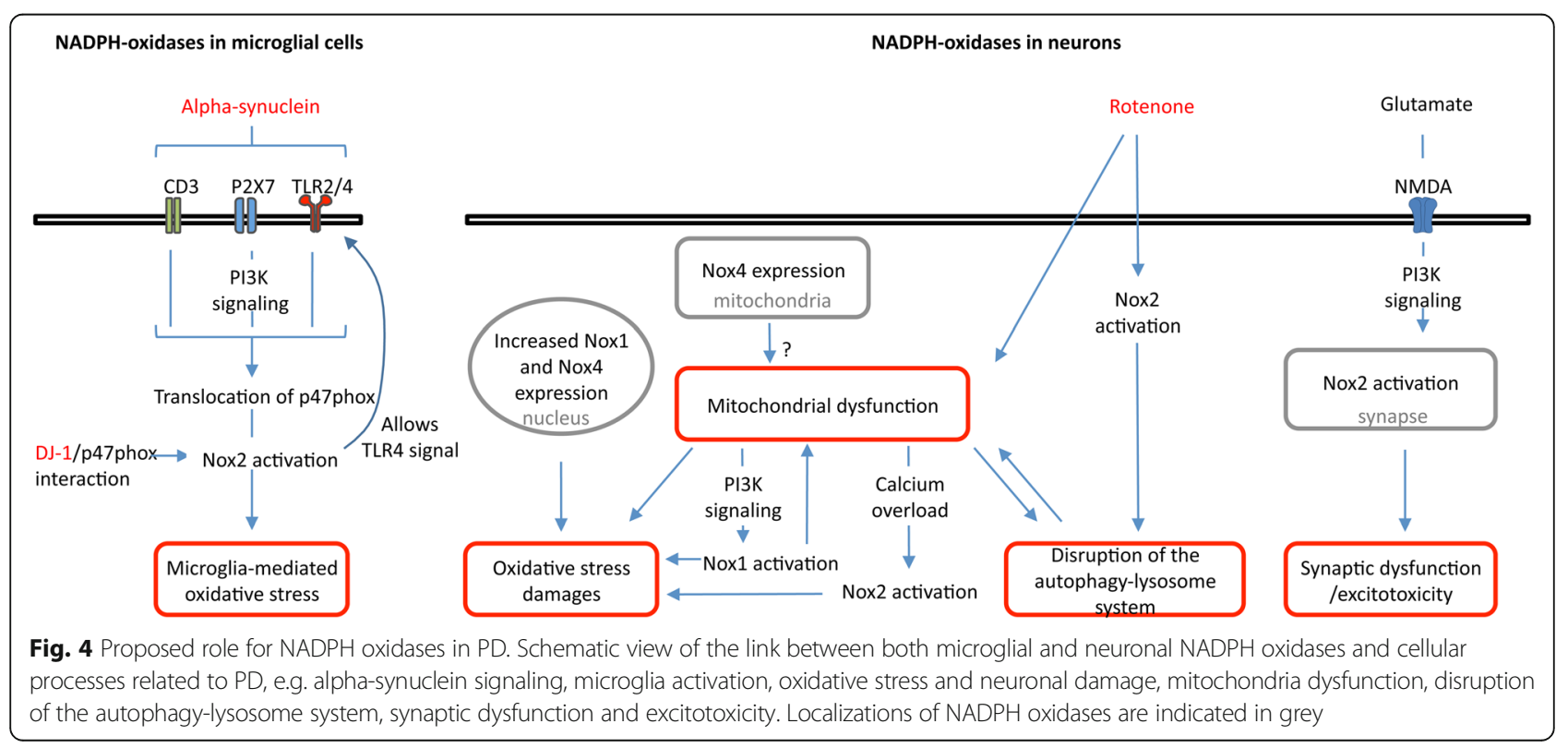




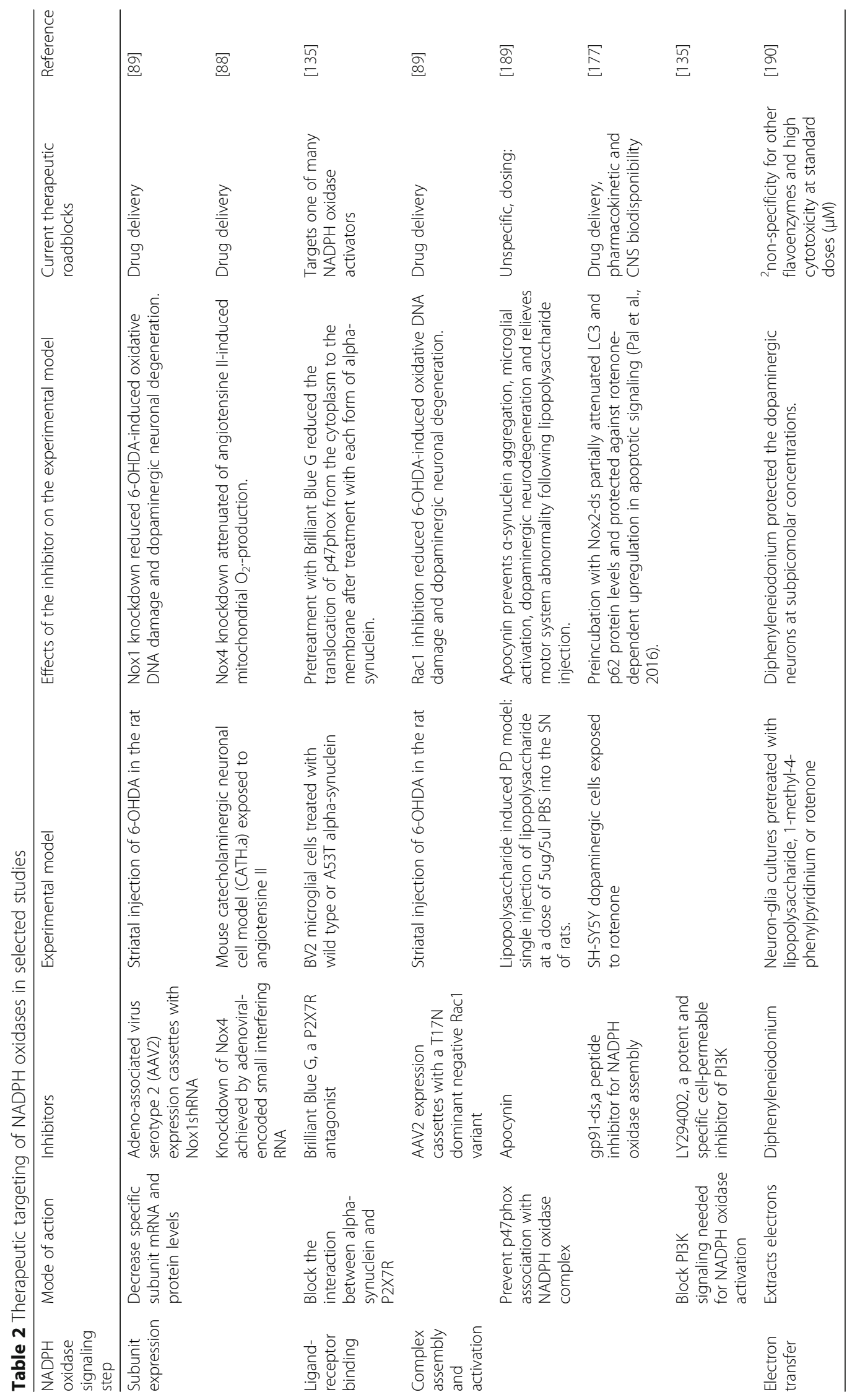




\section{NADPH oxidases inhibitors as potential therapeutic agents in PD}

To date, strategies directly targeting oxidative stress in PD have been typically focused on compounds that scavenge reactive oxygen species after they have been produced and on mitochondria-targeting therapeutics. Despite the importance of oxidative stress and mitochondria in PD, these strategies have shown mitigated or no success in clinical trials [180]. Modulating NADPH oxidases activity would represent a logical alternative to modify the course of PD, as it targets enzymatic complexes that are solely dedicated to the production of reactive oxygen species and that regulate cellular processes that are disrupted in PD (Fig. 4).

Different steps that are essential for NADPH oxidases enzymatic activity can be targeted. These include (i) the expression of NADPH oxidases subunits, (ii) the ligandreceptor binding, (iii) the complex assembly and its activation (including inhibiting signaling pathways such as PI3K signaling) as well as (iv) electron transfer. As illustrated in Table 2, several of these targets have been partially evaluated using either in vitro or in vivo experimental models of PD. These preclinical studies appear overall promising with for example decreases in markers of oxidative stress, in markers of autophagy-lysosomal defects or in neurodegeneration (Table 2). Beside knock-out mouse models and interfering RNAs, several small compounds or antibodies and peptides have been postulated as NADPH oxidases inhibitors. For a critical overview of the NADPH oxidases inhibitors, we refer the reader to the review of Altenhöfer and colleagues [52]. Briefly, the historical Nox2 inhibitors diphenylene iodonium and apocynin are commonly used but are unspecific and their effects cannot be solely attributed to inhibition of Nox2 or even NADPH oxidases [181]. More recently, several compounds inhibitors have been identified by rational drug discovery approaches and characterized with regards to NADPH oxidases selectivity and potential off-target effects. For example, ML171 is a potent Nox1 inhibitor with $\mathrm{IC}_{50}$ value of $130-150 \mathrm{nM}$ for Nox1 and of 3-5 $\mu \mathrm{M}$ for Nox2-4. GKT136901 [182, 183] and GKT137831 [184] are two structurally related compounds developed by Genkyotex. They potently inhibit Nox1, Nox4 and Nox5 with $\sim 10$ lower $\mathrm{IC}_{50}$ value than for Nox 2 inhibition. They are orally bio-available and have favorable ADME profiles [183, 184] and have consequently been evaluated across a range of disease models. GKT137831 has progressed through preclinical development and into clinical trials and thus appears as a good pharmacological tool for in vivo studies on the role of Nox1, Nox4 and Nox5 NADPH-oxidases enzymes in disease [185]. Peptide-based inhibitors such as Nox2-ds-tat, by their nature, have the potential advantage of being more specific and having fewer off-target effects than small-molecule organic compounds. However these peptides have disadvantages as well, such as low bioavailability and metabolic liability and - over time - induction of neutralizing antibodies. Overall, the high degree of structural and catalytic homology between the different catalytic subunits of NADPH oxidases makes finding selective inhibitors a challenge. However, as proposed by Diebold and collaborators several protein-protein interactions could in principle be targeted with new highthroughput assays. For example, targeting the binding of p67phox to p47phox or the binding of p47 to the membrane are suggested specific approaches to block the assembly of the active complex of Nox2 [186].

Beside the roadblocks having to do with delivery, pharmacokinetic, biodisponibility and specificity, the use of NADPH oxidases inhibitors will necessitate to determine the percent inhibition that could modify PD development while preserving physiological activity. NADPH oxidases have essential functions in host defense, regulation of cell growth and differentiation, regulation of vascular tone and of blood pressure [187], regulation of renal function [188] and, as broached in this review, in normal functioning of neurons. As such, excessive inhibition of NADPH oxidases could contribute to increased risk for infections, autoimmune disorders and/or tumor development, as well as cardiovascular diseases for example. Determining the therapeutic window for efficacy with minimal side effects is therefore needed for the acceptance of NADPH oxidases inhibitors as therapeutic agents in PD.

\section{Conclusions}

Data are already available suggesting pathologically relevant implications of NADPH oxidases in PD. Due to overlapping expression of Nox1, Nox2, Nox4 in microglia, and neurons, it remains difficult to dissect the relative involvement of the different NADPH oxidases family members in the dopaminergic degeneration. Development of microglia or neuron-selective gene knockout models or functional rescue experiments in a constitutive knockout background may resolve this issue in the future. In parallel, identification through rational drug discovery approaches of inhibitors specific for a given NADPH oxidase is needed to further demonstrate the therapeutic potential of NADPH oxidases in PD. Nox2 potentiates microglia proinflammatory phenotype and its overactivation is observed both in patients and in response to several toxins associated with parkinsonism. Because P47phox (i) appears as the ratelimiting factor for Nox2 activation, (ii) directly binds to DJ-1 and (iii) is phosphorylated by several kinases activated downstream of pathways activated by alphasynuclein, it is a potentially important target for the development of therapeutic agents against PD. The PI3K/Akt/ mTOR pathway that is deregulated in PD and that promotes NADPH oxidases activity also appears as a signaling pathway to be considered for the development of therapeutic strategies. The neuronal Nox1 and Nox4 that 
are upregulated in dopaminergic neurons of patients are also of prime interest although more studies are needed to evaluate the role of other NADPH oxidases in dopaminergic degeneration and to potentially identify isoformspecific pathways. Of importance, the evaluation of $\mathrm{NADPH}$ oxidases targeting therapeutics should be based not only on the detection of reactive oxygen species and oxidative damages, but also in regards to the energy failure associated with mitochondria dysfunction, the synaptic dysfunction and the disruption of the autophagy-lysosome associated with PD.

\begin{abstract}
Abbreviations
6-OHDA: 6-hydroxydopamine; AAV2: Adeno-associated virus serotype 2; ERK: Extracellular signal-regulated kinase; FAD: Flavin adenine dinucleotide; HMGB1: High mobility group box protein 1; LC3: Microtubule-associated protein 1A/1B-light chain 3; MAC-1: Macrophage antigen complex-1; MAPK: Mitogen-activated protein kinases; MPTP: 1-Methyl-4-phenyl-1,2,3,6tetrahydropyridine; mTOR: Mammalian target of rapamycin;

NADPH: Nicotinamide adenine dinucleotide phosphate; NMDA: N-methyl-Daspartate; PAK: P21-activated kinase; PD: Parkinson's disease;

PI3K: Phosphoinositide 3-kinases; PINK1: PTEN-induced kinase 1; Toll-like receptor; TNF: Tumor necrosis factor
\end{abstract}

\section{Acknowledgements}

The authors would like to thank the Neurological Clinic Department of CHRU of Lille and the Department of Pharmacology of the Faculty of Pharmacy of Lille and the JPArc Inserm UMRS 1172 and in particular the other members of the "Early-stages Parkinson's disease" team.

\section{Funding}

This work was supported by funding from the French Ministry of Health, the University of Lille, INSERM, CNRS, the region Haut-de-France and Dementia in Neurological and Mental Diseases (DN2M).

\section{Availability of data and materials}

Not applicable.

\section{Authors' contributions}

KB did the majority of the appropriate literature search and predominantly contributed to the writing of the article. EC assisted with the literature search and the drafting of the manuscript. $A D$ and $B G$ revised the manuscript providing expertise in PD and Pharmacology. MCCH extensively edited the manuscript providing expertise in molecular neurodegeneration in PD. All authors read and approved the final manuscript.

\section{Ethics approval and consent to participate}

Not applicable.

\section{Consent for publication}

Not applicable.

\section{Competing interests}

The authors declare that they have no competing interests.

\section{Publisher's Note}

Springer Nature remains neutral with regard to jurisdictional claims in published maps and institutional affiliations.

Received: 14 July 2017 Accepted: 25 October 2017

Published online: 13 November 2017

\section{References}

1. Dauer W, Przedborski S. Parkinson's disease: mechanisms and models. Neuron. 2003;39:889-909.

2. Spillantini MG, Schmidt ML, Lee VM, Trojanowski JQ, Jakes R, Goedert M Alpha-synuclein in Lewy bodies. Nature. 1997;388:839-40.
3. Lashuel HA, Overk CR, Oueslati A, Masliah E. The many faces of alphasynuclein: from structure and toxicity to therapeutic target. Nat Rev Neurosci. 2013;14:38-48.

4. Lee HJ, Patel S, Lee SJ. Intravesicular localization and exocytosis of alphasynuclein and its aggregates. J Neurosci. 2005;25:6016-24.

5. Jang A, Lee HJ, Suk JE, Jung JW, Kim KP, Lee SJ. Non-classical exocytosis of alpha-synuclein is sensitive to folding states and promoted under stress conditions. J Neurochem. 2010;113:1263-74.

6. Gerhard A, Pavese N, Hotton G, Turkheimer F, Es M, Hammers A, Eggert K, et al. In vivo imaging of microglial activation with [11C](R)-PK11195 PET in idiopathic Parkinson's disease. Neurobiol Dis. 2006;21:404-12.

7. Bezard E, Dovero S, Prunier C, Ravenscroft P, Chalon S, Guilloteau D, Crossman AR, et al. Relationship between the appearance of symptoms and the level of nigrostriatal degeneration in a progressive 1-methyl-4-phenyl1,2,3,6-tetrahydropyridine-lesioned macaque model of Parkinson's disease. J Neurosci. 2001;21:6853-61.

8. Arkadir D, Bergman H, Fahn S. Redundant dopaminergic activity may enable compensatory axonal sprouting in Parkinson disease. Neurology. 2014:82:1093-8.

9. Lloyd KG. CNS compensation to dopamine neuron loss in Parkinson's disease. Adv Exp Med Biol. 1977:90:255-66.

10. Polymeropoulos MH, Lavedan C, Leroy E, Ide SE, Dehejia A, Dutra A, Pike B, et al. Mutation in the alpha-synuclein gene identified in families with Parkinson's disease. Science. 1997;276:2045-7.

11. Singleton AB, Farrer $M$, Johnson J, Singleton A, Hague S, Kachergus J, Hulihan M, et al. Alpha-Synuclein locus triplication causes Parkinson's disease. Science. 2003;302:841.

12. Chartier-Harlin MC, Kachergus J, Roumier C, Mouroux V, Douay X, Lincoln S, Levecque C, et al. Alpha-synuclein locus duplication as a cause of familial Parkinson's disease. Lancet. 2004:364:1167-9.

13. Ibanez $P$, Bonnet AM, Debarges B, Lohmann E, Tison F, Pollak P, Agid Y, et al. Causal relation between alpha-synuclein gene duplication and familial Parkinson's disease. Lancet. 2004;364:1169-71.

14. Maraganore DM, de Andrade M, Elbaz A, Farrer MJ, loannidis JP, Kruger R, Rocca WA, et al. Collaborative analysis of alpha-synuclein gene promoter variability and Parkinson disease. JAMA. 2006;296:661-70.

15. Simon-Sanchez J, Schulte C, Bras JM, Sharma M, Gibbs JR, Berg D, PaisanRuiz C, et al. Genome-wide association study reveals genetic risk underlying Parkinson's disease. Nat Genet. 2009;41:1308-12.

16. Hernandez DG, Reed X, Singleton AB. Genetics in Parkinson disease: Mendelian versus non-Mendelian inheritance. J Neurochem. 2016;139(Suppl 1):59-74.

17. Gomez-Suaga P, Hilfiker S. LRRK2 as a modulator of lysosomal calcium homeostasis with downstream effects on autophagy. Autophagy. 2012;8: 692-3.

18. Mullin S, Schapira A. The genetics of Parkinson's disease. Br Med Bull. 2015; 114:39-52.

19. Hamza TH, Zabetian CP, Tenesa A, Laederach A, Montimurro J, Yearout D, Kay DM, et al. Common genetic variation in the HLA region is associated with late-onset sporadic Parkinson's disease. Nat Genet. 2010;42:781-5.

20. Holmans P, Moskvina V, Jones L, Sharma M, Vedernikov A, Buchel F, Saad M, et al. A pathway-based analysis provides additional support for an immunerelated genetic susceptibility to Parkinson's disease. Hum Mol Genet. 2013; 22:1039-49.

21. Witoelar A, Jansen IE, Wang Y, Desikan RS, Gibbs JR, Blauwendraat C, Thompson WK, et al. Genome-wide Pleiotropy between Parkinson disease and autoimmune diseases. JAMA Neurol. 2017;74:780-92.

22. Dias V, Junn E, Mouradian MM. The role of oxidative stress in Parkinson's disease. J Parkinsons Dis. 2013;3:461-91.

23. Michel PP, Hirsch EC, Hunot S. Understanding Dopaminergic cell death pathways in Parkinson disease. Neuron. 2016;90:675-91.

24. Elbaz A, Moisan F. The scientific bases to consider Parkinson's disease an occupational disease in agriculture professionals exposed to pesticides in France. J Epidemiol Community Health. 2016;70:319-21.

25. Chin-Chan M, Navarro-Yepes J, Quintanilla-Vega B. Environmental pollutants as risk factors for neurodegenerative disorders: Alzheimer and Parkinson diseases. Front Cell Neurosci. 2015;9:124.

26. Bove J, Perier C. Neurotoxin-based models of Parkinson's disease. Neuroscience. 2012;211:51-76.

27. Olanow CW. Oxidation reactions in Parkinson's disease. Neurology. 1990;40: Suppl 32-7. discussion 37-39. 
28. Winklhofer KF, Haass C. Mitochondrial dysfunction in Parkinson's disease Biochim Biophys Acta. 2010;1802:29-44.

29. Alam Zl, Jenner A, Daniel SE, Lees AJ, Cairns N, Marsden CD, Jenner P, et al. Oxidative DNA damage in the parkinsonian brain: an apparent selective increase in 8-hydroxyguanine levels in substantia nigra. J Neurochem. 1997; 69:1196-203.

30. Dexter DT, Carter CJ, Wells FR, Javoy-Agid F, Agid Y, Lees A, Jenner P, et al. Basal lipid peroxidation in substantia nigra is increased in Parkinson's disease. J Neurochem. 1989;52:381-9.

31. Zhang J, Perry G, Smith MA, Robertson D, Olson SJ, Graham DG, Montine TJ. Parkinson's disease is associated with oxidative damage to cytoplasmic DNA and RNA in substantia nigra neurons. Am J Pathol. 1999;154:1423-9.

32. Sofic $E$, Lange KW, Jellinger $K$, Riederer $P$. Reduced and oxidized glutathione in the substantia nigra of patients with Parkinson's disease. Neurosci Lett. 1992;142:128-30.

33. Damier $P$, Hirsch EC, Zhang P, Agid Y, Javoy-Agid F. Glutathione peroxidase, glial cells and Parkinson's disease. Neuroscience. 1993;52:1-6.

34. Mittelbronn M, Dietz K, Schluesener HJ, Meyermann R. Local distribution of microglia in the normal adult human central nervous system differs by up to one order of magnitude. Acta Neuropathol. 2001;101:249-55.

35. Lawson LJ, Perry VH, Dri P, Gordon S. Heterogeneity in the distribution and morphology of microglia in the normal adult mouse brain. Neuroscience. 1990;39:151-70.

36. Schapira AH, Cooper JM, Dexter D, Clark JB, Jenner P, Marsden CD. Mitochondrial complex I deficiency in Parkinson's disease. J Neurochem. 1990;54:823-7.

37. Schapira AH, Mann VM, Cooper JM, Dexter D, Daniel SE, Jenner P, Clark JB, et al. Anatomic and disease specificity of NADH CoQ1 reductase (complex I) deficiency in Parkinson's disease. J Neurochem. 1990;55:2142-5.

38. Mizuno Y, Ohta S, Tanaka M, Takamiya S, Suzuki K, Sato T, Oya H, et al. Deficiencies in complex I subunits of the respiratory chain in Parkinson's disease. Biochem Biophys Res Commun. 1989;163:1450-5.

39. Rossi F, Zatti M. Biochemical aspects of phagocytosis in polymorphonuclear leucocytes. NADH and NADPH oxidation by the granules of resting and phagocytizing cells. Experientia. 1964;20:21-3.

40. Segal AW. How neutrophils kill microbes. Annu Rev Immunol. 2005;23:197-223.

41. Banfi B, Maturana A, Jaconi S, Arnaudeau S, Laforge T, Sinha B, Ligeti E, et al. A mammalian $\mathrm{H}+$ channel generated through alternative splicing of the NADPH oxidase homolog NOH-1. Science. 2000;287:138-42.

42. Suh YA, Arnold RS, Lassegue B, Shi J, Xu X, Sorescu D, Chung AB, et al. Cell transformation by the superoxide-generating oxidase Mox1. Nature. 1999; 401:79-82.

43. Cheng G, Cao Z, Xu X, van Meir EG, Lambeth JD. Homologs of gp91phox: cloning and tissue expression of Nox3, Nox4, and Nox5. Gene. 2001;269:131-40.

44. Geiszt M, Kopp JB, Varnai $P$, Leto TL. Identification of renox, an NAD(P)H oxidase in kidney. Proc Natl Acad Sci U S A. 2000;97:8010-4.

45. Shiose A, Kuroda J, Tsuruya K, Hirai M, Hirakata H, Naito S, Hattori M, et al. A novel superoxide-producing NAD(P)H oxidase in kidney. J Biol Chem. 2001; 276:1417-23.

46. Banfi B, Molnar G, Maturana A, Steger K, Hegedus B, Demaurex N, Krause $\mathrm{KH}$. A ca(2+)-activated NADPH oxidase in testis, spleen, and lymph nodes. J Biol Chem. 2001;276:37594-601.

47. De Deken X, Wang D, Many MC, Costagliola S, Libert F, Vassart G, Dumont $\mathrm{JE}$, et al. Cloning of two human thyroid CDNAs encoding new members of the NADPH oxidase family. J Biol Chem. 2000;275:23227-33.

48. Edens WA, Sharling L, Cheng G, Shapira R, Kinkade JM, Lee T, Edens HA, et al. Tyrosine cross-linking of extracellular matrix is catalyzed by Duox, a multidomain oxidase/peroxidase with homology to the phagocyte oxidase subunit gp91phox. J Cell Biol. 2001;154:879-91.

49. Meitzler JL, Hinde S, Banfi B, Nauseef WM. Ortiz de Montellano PR. Conserved cysteine residues provide a protein-protein interaction surface in dual oxidase (DUOX) proteins. J Biol Chem. 2013;288:7147-57.

50. Meitzler JL. Ortiz de Montellano PR. Caenorhabditis Elegans and human dual oxidase 1 (DUOX1) "peroxidase" domains: insights into heme binding and catalytic activity. J Biol Chem. 2009;284:18634-43.

51. Meitzler JL, Ortiz de Montellano PR. Structural stability and heme binding potential of the truncated human dual oxidase 2 (DUOX2) peroxidase domain. Arch Biochem Biophys. 2011;512:197-203.

52. Altenhofer S, Radermacher KA, Kleikers PW, Wingler K, Schmidt HH. Evolution of NADPH Oxidase inhibitors: selectivity and mechanisms for target engagement. Antioxid Redox Signal. 2015;23:406-27.
53. Kawahara T, Quinn MT, Lambeth JD. Molecular evolution of the reactive oxygen-generating NADPH oxidase (Nox/Duox) family of enzymes. BMC Evol Biol. 2007;7:109.

54. Lambeth JD, Kawahara T, Diebold B. Regulation of Nox and Duox enzymatic activity and expression. Free Radic Biol Med. 2007;43:319-31.

55. Yu L, Quinn MT, Cross AR, Dinauer MC. Gp91(phox) is the heme binding subunit of the superoxide-generating NADPH oxidase. Proc Natl Acad Sci U S A. 1998;95:7993-8.

56. De Leo FR, Ulman KV, Davis AR, Jutila KL, Quinn MT. Assembly of the human neutrophil NADPH oxidase involves binding of p67phox and flavocytochrome b to a common functional domain in p47phox. J Biol Chem. 1996:271:17013-20.

57. Han CH, Freeman JL, Lee T, Motalebi SA, Lambeth JD. Regulation of the neutrophil respiratory burst oxidase. Identification of an activation domain in p67(phox). J Biol Chem. 1998;273:16663-8.

58. Roepstorff K, Rasmussen I, Sawada M, Cudre-Maroux C, Salmon P, Bokoch G, van Deurs B, et al. Stimulus-dependent regulation of the phagocyte NADPH oxidase by a VAV1, Rac1, and PAK1 signaling axis. J Biol Chem. 2008;283: 7983-93.

59. Kim C, Dinauer MC. Impaired NADPH oxidase activity in Rac2-deficient murine neutrophils does not result from defective translocation of p47phox and p67phox and can be rescued by exogenous arachidonic acid. J Leukoc Biol. 2006;79:223-34

60. Korchak HM, Rossi MW, Kilpatrick LE. Selective role for beta-protein kinase C in signaling for $0-2$ generation but not degranulation or adherence in differentiated HL60 cells. J Biol Chem. 1998;273:27292-9.

61. Bey EA, Xu B, Bhattacharjee A, Oldfield CM, Zhao X, Li Q, Subbulakshmi V, et al. Protein kinase $C$ delta is required for p47phox phosphorylation and translocation in activated human monocytes. J Immunol. 2004;173:5730-8.

62. Waki K, Inanami O, Yamamori T, Nagahata H, Kuwabara M. Involvement of protein kinase Cdelta in the activation of NADPH oxidase and the phagocytosis of neutrophils. Free Radic Res. 2006;40:359-67.

63. Hoyal CR, Gutierrez A, Young BM, Catz SD, Lin JH, Tsichlis PN, Babior BM Modulation of p47PHOX activity by site-specific phosphorylation: Aktdependent activation of the NADPH oxidase. Proc Natl Acad Sci U S A. 2003;100:5130-5.

64. Chen Q, Powell DW, Rane MJ, Singh S, Butt W, Klein JB, McLeish KR. Akt phosphorylates p47phox and mediates respiratory burst activity in human neutrophils. J Immunol. 2003;170:5302-8.

65. Dang PM, Stensballe A, Boussetta T, Raad H, Dewas C, Kroviarski Y, Hayem $G$, et al. A specific p47phox -serine phosphorylated by convergent MAPKs mediates neutrophil NADPH oxidase priming at inflammatory sites. J Clin Invest. 2006;116:2033-43.

66. Martyn KD, Kim MJ, Quinn MT, Dinauer MC, Knaus UG. p21-activated kinase (Pak) regulates NADPH oxidase activation in human neutrophils. Blood. 2005;106:3962-9.

67. Dewas C, Dang PM, Gougerot-Pocidalo MA, El-Benna J. TNF-alpha induces phosphorylation of p47(phox) in human neutrophils: partial phosphorylation of p47phox is a common event of priming of human neutrophils by TNFalpha and granulocyte-macrophage colony-stimulating factor. J Immunol. 2003;171:4392-8.

68. Martyn KD, Frederick LM, von Loehneysen K, Dinauer MC, Knaus UG. Functional analysis of Nox4 reveals unique characteristics compared to other NADPH oxidases. Cell Signal. 2006;18:69-82.

69. Serrander L, Cartier L, Bedard K, Banfi B, Lardy B, Plastre O, Sienkiewicz A, et al. NOX4 activity is determined by mRNA levels and reveals a unique pattern of ROS generation. Biochem J. 2007:406:105-14.

70. Basuroy S, Tcheranova D, Bhattacharya S, Leffler CW, Parfenova H. Nox4 NADPH oxidase-derived reactive oxygen species, via endogenous carbon monoxide, promote survival of brain endothelial cells during TNF-alphainduced apoptosis. Am J Physiol Cell Physiol. 2011;300:C256-65.

71. Meng D, Lv DD, Fang J. Insulin-like growth factor-I induces reactive oxygen species production and cell migration through Nox4 and Rac1 in vascular smooth muscle cells. Cardiovasc Res. 2008;80:299-308.

72. Martin-Garrido A, Brown DI, Lyle AN, Dikalova A, Seidel-Rogol B, Lassegue B, San Martin A, et al. NADPH oxidase 4 mediates TGF-beta-induced smooth muscle alpha-actin via p38MAPK and serum response factor. Free Radic Biol Med. 2011;50:354-62.

73. Jagnandan D, Church JE, Banfi B, Stuehr DJ, Marrero MB, Fulton DJ. Novel mechanism of activation of NADPH oxidase 5 . Calcium sensitization via phosphorylation. J Biol Chem. 2007;282:6494-507. 
74. Bedard K, Krause KH. The NOX Family of ROS-generating NADPH oxidases: physiology and pathophysiology. Physiol Rev. 2007;87:245-313.

75. Maru Y, Nishino T, Kakinuma K. Expression of Nox genes in rat organs, mouse oocytes, and sea urchin eggs. DNA Seq. 2005;16:83-8.

76. Harrigan TJ, Abdullaev IF, Jourd'heuil D, Mongin AA. Activation of microglia with zymosan promotes excitatory amino acid release via volume-regulated anion channels: the role of NADPH oxidases. J Neurochem. 2008;106:2449-62.

77. Sankarapandi S, Zweier JL, Mukherjee G, Quinn MT, Huso DL. Measurement and characterization of superoxide generation in microglial cells: evidence for an NADPH oxidase-dependent pathway. Arch Biochem Biophys. 1998; 353:312-21.

78. Green SP, Cairns B, Rae J, Errett-Baroncini C, Hongo JA, Erickson RW, Curnutte JT. Induction of gp91-phox, a component of the phagocyte NADPH oxidase, in microglial cells during central nervous system inflammation. J Cereb Blood Flow Metab. 2001;21:374-84.

79. Cheret C, Gervais A, Lelli A, Colin C, Amar L, Ravassard P, Mallet J, et al Neurotoxic activation of microglia is promoted by a nox 1-dependent NADPH oxidase. J Neurosci. 2008;28:12039-51.

80. Li B, Bedard K, Sorce S, Hinz B, Dubois-Dauphin M, Krause KH. NOX4 expression in human microglia leads to constitutive generation of reactive oxygen species and to constitutive IL-6 expression. J Innate Immun. 2009;1: 570-81.

81. Mead EL, Mosley A, Eaton S, Dobson L, Heales SJ, Pocock JM. Microglial neurotransmitter receptors trigger superoxide production in microglia; consequences for microglial-neuronal interactions. J Neurochem. 2012;121: 287-301.

82. Vilhardt F, van Deurs B. The phagocyte NADPH oxidase depends on cholesterol-enriched membrane microdomains for assembly. EMBO J. 2004; 23:739-48

83. Ejlerskov P, Christensen DP, Beyaie D, Burritt JB, Paclet MH, Gorlach A, van Deurs $B$, et al. NADPH oxidase is internalized by clathrin-coated pits and localizes to a Rab27A/B GTPase-regulated secretory compartment in activated macrophages. J Biol Chem. 2012;287:4835-52.

84. Ibi M, Katsuyama M, Fan C, Iwata K, Nishinaka T, Yokoyama T, YabeNishimura C. NOX1/NADPH oxidase negatively regulates nerve growth factor-induced neurite outgrowth. Free Radic Biol Med. 2006:40:1785-95.

85. Tammariello SP, Quinn MT, Estus S. NADPH oxidase contributes directly to oxidative stress and apoptosis in nerve growth factor-deprived sympathetic neurons. J Neurosci. 2000;20:RC53.

86. Kim MJ, Shin KS, Chung YB, Jung KW, Cha Cl, Shin DH. Immunohistochemical study of p47Phox and gp91Phox distributions in rat brain. Brain Res. 2005;1040:178-86.

87. Vallet $P$, Charnay $Y$, Steger K, Ogier-Denis E, Kovari E, Herrmann F, Michel JP, et al. Neuronal expression of the NADPH oxidase NOX4, and its regulation in mouse experimental brain ischemia. Neuroscience. 2005;132:233-8.

88. Case AJ, Li S, Basu U, Tian J, Zimmerman MC. Mitochondrial-localized NADPH oxidase 4 is a source of superoxide in angiotensin II-stimulated neurons. Am J Physiol Heart Circ Physiol. 2013;305:H19-28.

89. Choi DH, Cristovao AC, Guhathakurta S, Lee J, Joh TH, Beal MF, Kim YS. NADPH oxidase 1-mediated oxidative stress leads to dopamine neuron death in Parkinson's disease. Antioxid Redox Signal. 2012;16:1033-45.

90. Zawada WM, Mrak RE, Biedermann J, Palmer QD, Gentleman SM, Aboud O, Griffin WS. Loss of angiotensin II receptor expression in dopamine neurons in Parkinson's disease correlates with pathological progression and is accompanied by increases in Nox4- and 8-OH guanosine-related nucleic acid oxidation and caspase-3 activation. Acta Neuropathol Commun. 2015;3:9.

91. Abramov AY, Jacobson J, Wientjes F, Hothersall J, Canevari L, Duchen MR. Expression and modulation of an NADPH oxidase in mammalian astrocytes. J Neurosci. 2005;25:9176-84.

92. Oshitani N, Kitano A, Okabe H, Nakamura S, Matsumoto T, Kobayashi K. Location of nitroblue tetrazolium-reducing activity in human colonic mucosa obtained by biopsy. Dig Dis Sci. 1993;38:546-50.

93. Panday A, Sahoo MK, Osorio D, Batra S. NADPH oxidases: an overview from structure to innate immunity-associated pathologies. Cell Mol Immunol. 2015;12:5-23.

94. Kishida KT, Pao M, Holland SM, Klann E. NADPH oxidase is required for NMDA receptor-dependent activation of ERK in hippocampal area CA1. J Neurochem. 2005:94:299-306.

95. Kishida KT, Hoeffer CA, Hu D, Pao M, Holland SM, Klann E. Synaptic plasticity deficits and mild memory impairments in mouse models of chronic granulomatous disease. Mol Cell Biol. 2006;26:5908-20.
96. Perry VH. A revised view of the central nervous system microenvironment and major histocompatibility complex class II antigen presentation. J Neuroimmunol. 1998;90:113-21.

97. Hirsch EC, Vyas S, Hunot S. Neuroinflammation in Parkinson's disease. Parkinsonism Relat Disord. 2012;18:S210-2.

98. Wu DC, Teismann P, Tieu K, Vila M, Jackson-Lewis V, Ischiropoulos $H_{\text {, }}$ Przedborski S. NADPH oxidase mediates oxidative stress in the 1-methyl-4 phenyl-1,2,3,6-tetrahydropyridine model of Parkinson's disease. Proc Natl Acad Sci U S A. 2003;100:6145-50.

99. L'Episcopo F, Tirolo C, Testa N, Caniglia S, Morale MC, Deleidi M, Serapide MF, et al. Plasticity of subventricular zone neuroprogenitors in MPTP (1methyl-4-phenyl-1,2,3,6-tetrahydropyridine) mouse model of Parkinson's disease involves cross talk between inflammatory and Wnt/beta-catenin signaling pathways: functional consequences for neuroprotection and repair. J Neurosci. 2012;32:2062-85.

100. Wu DC, Jackson-Lewis V, Vila M, Tieu K, Teismann P, Vadseth C, Choi DK, et al. Blockade of microglial activation is neuroprotective in the 1-methyl-4phenyl-1,2,3,6-tetrahydropyridine mouse model of Parkinson disease. J Neurosci. 2002;22:1763-71.

101. Huh SH, Chung YC, Piao Y, Jin MY, Son HJ, Yoon NS, Hong JY, et al. Ethyl pyruvate rescues nigrostriatal dopaminergic neurons by regulating glial activation in a mouse model of Parkinson's disease. J Immunol. 2011;187:960-9.

102. Zhang W, Gao JH, Yan ZF, Huang XY, Guo P, Sun L, Liu Z, et al. Minimally toxic dose of Lipopolysaccharide and alpha-Synuclein Oligomer elicit synergistic Dopaminergic Neurodegeneration: role and mechanism of Microglial NOX2 activation. Mol Neurobiol. 2016,[ahead of print].

103. Purisai MG, McCormack AL, Cumine S, Li J, Isla MZ, Di Monte DA. Microglial activation as a priming event leading to paraquat-induced dopaminergic cell degeneration. Neurobiol Dis. 2007;25:392-400.

104. Hernandes MS, Santos GD, Cafe-Mendes CC, Lima LS, Scavone C, Munhoz $C D$, Britto LR. Microglial cells are involved in the susceptibility of NADPH oxidase knockout mice to 6-hydroxy-dopamine-induced neurodegeneration. PLoS One. 2013;8:e75532.

105. Rodriguez-Pallares J, Parga JA, Munoz A, Rey P, Guerra MJ, Labandeira-Garcia $J$. Mechanism of 6-hydroxydopamine neurotoxicity: the role of NADPH oxidase and microglial activation in 6-hydroxydopamine-induced degeneration of dopaminergic neurons. J Neurochem. 2007;103:145-56.

106. Wang Y, Liu D, Zhang H, Wei L, Liu Y, Liao J, Gao HM, et al. Ultrafine carbon particles promote rotenone-induced dopamine neuronal loss through activating microglial NADPH oxidase. Toxicol Appl Pharmacol. 2017;322:519.

107. Kumar A, Stoica BA, Sabirzhanov B, Burns MP, Faden Al, Loane DJ. Traumatic brain injury in aged animals increases lesion size and chronically alters microglial/macrophage classical and alternative activation states. Neurobiol Aging. 2013;34:1397-411.

108. Byrnes KR, Loane DJ, Stoica BA, Zhang J, Faden Al. Delayed mGluR5 activation limits neuroinflammation and neurodegeneration after traumatic brain injury. J Neuroinflammation. 2012;9:43.

109. Kumar A, Barrett JP, Alvarez-Croda DM, Stoica BA, Faden Al, Loane DJ. NOX2 drives M1-like microglial/macrophage activation and neurodegeneration following experimental traumatic brain injury. Brain Behav Immun. 2016;58: 291-309.

110. Hunot S, Dugas N, Faucheux B, Hartmann A, Tardieu M, Debre P, Agid $Y$, et al. FcepsilonRII/CD23 is expressed in Parkinson's disease and induces, in vitro, production of nitric oxide and tumor necrosis factor-alpha in glial cells. J Neurosci. 1999;19:3440-7.

111. Mogi M, Harada M, Riederer P, Narabayashi H, Fujita K, Nagatsu T. Tumor necrosis factor-alpha (TNF-alpha) increases both in the brain and in the cerebrospinal fluid from parkinsonian patients. Neurosci Lett. 1994;165:208-10.

112. Mogi M, Harada M, Narabayashi $H$, Inagaki $H$, Minami M, Nagatsu T. Interleukin (IL)-1 beta, IL-2, IL-4, IL-6 and transforming growth factor-alpha levels are elevated in ventricular cerebrospinal fluid in juvenile parkinsonism and Parkinson's disease. Neurosci Lett. 1996;211:13-6.

113. Lehnardt S, Massillon L, Follett $P$, Jensen FE, Ratan R, Rosenberg PA, Volpe $J$, et al. Activation of innate immunity in the CNS triggers neurodegeneration through a toll-like receptor 4-dependent pathway. Proc Natl Acad Sci U S A. 2003;100:8514-9.

114. Qin L, Wu X, Block ML, Liu Y, Breese GR, Hong JS, Knapp DJ, et al. Systemic LPS causes chronic neuroinflammation and progressive neurodegeneration. Glia. 2007;55:453-62. 
115. Hanisch UK. Functional diversity of microglia - how heterogeneous are they to begin with? Front Cell Neurosci. 2013;7:65.

116. Martin HL, Teismann P. Glutathione-a review on its role and significance in Parkinson's disease. FASEB J. 2009;23:3263-72.

117. Poltorak A, He X, Smirnova I, Liu MY, Van Huffel C, Du X, Birdwell D, et al. Defective LPS signaling in $\mathrm{C} 3 \mathrm{H} / \mathrm{HeJ}$ and $\mathrm{C} 57 \mathrm{BL} / 10 \mathrm{ScCr}$ mice: mutations in Tlr4 gene. Science 1998;282:2085-8.

118. Hoshino K, Takeuchi O, Kawai T, Sanjo H, Ogawa T, Takeda Y, Takeda K, et al. Cutting edge: toll-like receptor 4 (TLR4)-deficient mice are hyporesponsive to lipopolysaccharide: evidence for TLR4 as the Lps gene product. J Immunol. 1999;162:3749-52

119. Qin L, Li G, Qian X, Liu Y, Wu X, Liu B, Hong JS, et al. Interactive role of the toll-like receptor 4 and reactive oxygen species in LPS-induced microglia activation. Glia. 2005;52:78-84.

120. Pei Z, Pang H, Qian L, Yang S, Wang T, Zhang W, Wu X, et al. MAC1 mediates LPS-induced production of superoxide by microglia: the role of pattern recognition receptors in dopaminergic neurotoxicity. Glia. 2007;55: 1362-73.

121. Qin L, Liu Y, Hong JS, Crews FT. NADPH oxidase and aging drive microglial activation, oxidative stress, and dopaminergic neurodegeneration following systemic LPS administration. Glia. 2013;61:855-68.

122. Qin L, Liu Y, Wang T, Wei SJ, Block ML, Wilson B, Liu B, et al. NADPH oxidase mediates lipopolysaccharide-induced neurotoxicity and proinflammatory gene expression in activated microglia. J Biol Chem. 2004;279:1415-21.

123. Wang Q, Oyarzabal E, Wilson B, Qian L, Hong JS. Substance P enhances microglial density in the substantia nigra through neurokinin-1 receptor/ NADPH oxidase-mediated chemotaxis in mice. Clin Sci (Lond). 2015;129: 757-67.

124. Gao HM, Liu B, Zhang W, Hong JS. Critical role of microglial NADPH oxidase-derived free radicals in the in vitro MPTP model of Parkinson's disease. FASEB J. 2003;17:1954-6.

125. Gao HM, Liu B, Zhang W, Hong JS. Synergistic dopaminergic neurotoxicity of MPTP and inflammogen lipopolysaccharide: relevance to the etiology of Parkinson's disease. FASEB J. 2003;17:1957-9.

126. Wu XF, Block ML, Zhang W, Qin L, Wilson B, Zhang WQ, Veronesi B, et al. The role of microglia in paraquat-induced dopaminergic neurotoxicity. Antioxid Redox Signal. 2005;7:654-61.

127. Gao HM, Liu B, Hong JS. Critical role for microglial NADPH oxidase in rotenone-induced degeneration of dopaminergic neurons. J Neurosci. 2003; 23:6181-7.

128. Zhang W, Wang T, Qin L, Gao HM, Wilson B, Ali SF, Hong JS, et al. Neuroprotective effect of dextromethorphan in the MPTP Parkinson's disease model: role of NADPH oxidase. FASEB J. 2004;18:589-91.

129. Hernandes MS, Cafe-Mendes CC, Britto LR. NADPH oxidase and the degeneration of dopaminergic neurons in parkinsonian mice. Oxidative Med Cell Longev. 2013;2013:157857.

130. Beraud D, Hathaway HA, Trecki J, Chasovskikh S, Johnson DA, Johnson JA Federoff $\mathrm{HJ}$, et al. Microglial activation and antioxidant responses induced by the Parkinson's disease protein alpha-synuclein. J Neurolmmune Pharmacol. 2013;8:94-117.

131. Codolo G, Plotegher N, Pozzobon T, Brucale M, Tessari I, Bubacco L, de Bernard M. Triggering of inflammasome by aggregated alpha-synuclein, an inflammatory response in synucleinopathies. PLoS One. 2013;8:e55375.

132. Kim C, Ho DH, Suk JE, You S, Michael S, Kang J, Joong Lee S, et al. Neuronreleased oligomeric alpha-synuclein is an endogenous agonist of TLR2 for paracrine activation of microglia. Nat Commun. 2013:1562.

133. Fellner $L$, Irschick $R$, Schanda $K$, Reindl $M$, Klimaschewski L, Poewe $W$, Wenning GK, et al. Toll-like receptor 4 is required for alpha-synuclein dependent activation of microglia and astroglia. Glia. 2013;61:349-60.

134. Zhang W, Dallas S, Zhang D, Guo JP, Pang H, Wilson B, Miller DS, et al. Microglial PHOX and Mac-1 are essential to the enhanced dopaminergic neurodegeneration elicited by A30P and A53T mutant alpha-synuclein. Glia. 2007:55:1178-88

135. Jiang T, Hoekstra J, Heng X, Kang W, Ding J, Liu J, Chen S, et al. P2X7 receptor is critical in alpha-synuclein-mediated microglial NADPH oxidase activation. Neurobiol Aging. 2015;36:2304-18.

136. Qiao H, Zhang Q, Yuan H, Li Y, Wang D, Wang R, He X. Elevated neuronal alpha-synuclein promotes microglia activation after spinal cord ischemic/ reperfused injury. Neuroreport. 2015;26:656-61.

137. Wang S, Chu CH, Guo M, Jiang L, Nie H, Zhang W, Wilson B, et al. Identification of a specific alpha-synuclein peptide (alpha-Syn 29-40) capable of eliciting microglial superoxide production to damage dopaminergic neurons. J Neuroinflammation. 2016;13:158.

138. Harms AS, Cao S, Rowse AL, Thome AD, Li X, Mangieri LR, Cron RQ, et al. $\mathrm{MHCll}$ is required for alpha-synuclein-induced activation of microglia, CD4 T cell proliferation, and dopaminergic neurodegeneration. J Neurosci. 2013;33: 9592-600.

139. Wang S, Chu CH, Stewart T, Ginghina C, Wang Y, Nie H, Guo M, et al. AlphaSynuclein, a chemoattractant, directs microglial migration via $\mathrm{H} 2 \mathrm{O} 2$-dependent Lyn phosphorylation. Proc Natl Acad Sci U S A. 2015;112:E1926-35.

140. Liu W, Wu H, Chen L, Wen Y, Kong X, Gao WQ. Park7 interacts with p47(phox) to direct NADPH oxidase-dependent ROS production and protect against sepsis. Cell Res. 2015;25:691-706.

141. Amatullah H, Shan Y, Beauchamp BL, Gali PL, Gupta S, Maron-Gutierrez T, Speck ER, et al. DJ-1/PARK7 impairs bacterial clearance in sepsis. Am J Respir Crit Care Med. 2017:195:889-905

142. Rodrigues-Sousa T, Ladeirinha AF, Santiago AR, Carvalheiro H, Raposo B, Alarcao A, Cabrita A, et al. Deficient production of reactive oxygen species leads to severe chronic DSS-induced colitis in Ncf1/p47phox-mutant mice. PLoS One. 2014;9:e97532.

143. Dzamko N, Geczy CL, Halliday GM. Inflammation is genetically implicated in Parkinson's disease. Neuroscience. 2015:302:89-102.

144. Schapansky J, Nardozzi JD, LaVoie MJ. The complex relationships between microglia, alpha-synuclein, and LRRK2 in Parkinson's disease. Neuroscience. 2015;302:74-88.

145. Tejada-Simon MV, Serrano F, Villasana LE, Kanterewicz BI, Wu GY, Quinn MT, Klann E. Synaptic localization of a functional NADPH oxidase in the mouse hippocampus. Mol Cell Neurosci. 2005;29:97-106.

146. Chamulitrat W, Schmidt R, Tomakidi P, Stremmel W, Chunglok W, Kawahara T, Rokutan K. Association of gp91phox homolog Nox1 with anchorageindependent growth and MAP kinase-activation of transformed human keratinocytes. Oncogene. 2003;22:6045-53.

147. Desouki MM, Kulawiec M, Bansal S, Das GM, Singh KK. Cross talk between mitochondria and superoxide generating NADPH oxidase in breast and ovarian tumors. Cancer Biol Ther. 2005:4:1367-73.

148. Kuroda J, Nakagawa K, Yamasaki T, Nakamura K, Takeya R, Kuribayashi F, Imajoh-Ohmi S, et al. The superoxide-producing NAD(P)H oxidase Nox4 in the nucleus of human vascular endothelial cells. Genes Cells. 2005;10:1139-51.

149. Cristovao AC, Choi DH, Baltazar G, Beal MF, Kim YS. The role of NADPH oxidase 1-derived reactive oxygen species in paraquat-mediated dopaminergic cell death. Antioxid Redox Signal. 2009;11:2105-18.

150. Cristovao AC, Guhathakurta S, Bok E, Je G, Yoo SD, Choi DH, Kim YS. NADPH oxidase 1 mediates alpha-synucleinopathy in Parkinson's disease. J Neurosci. 2012:32:14465-77.

151. Zhang FL, He Y, Zheng Y, Zhang WJ, Wang Q, Jia YJ, Song HL, et al. Therapeutic effects of fucoidan in 6-hydroxydopamine-lesioned rat model of Parkinson's disease: role of NADPH oxidase-1. CNS Neurosci Ther. 2014;20: 1036-44.

152. Braak H, Ghebremedhin E, Rub U, Bratzke H, Del Tredici K. Stages in the development of Parkinson's disease-related pathology. Cell Tissue Res. 2004; 318:121-34

153. Topchiy E, Panzhinskiy E, Griffin WS, Barger SW, Das M, Zawada WM. Nox4generated superoxide drives angiotensin II-induced neural stem cell proliferation. Dev Neurosci. 2013;35:293-305.

154. Zawada WM, Banninger GP, Thornton J, Marriott B, Cantu D, Rachubinski AL, Das $M$, et al. Generation of reactive oxygen species in 1-methyl-4phenylpyridinium (MPP+) treated dopaminergic neurons occurs as an NADPH oxidase-dependent two-wave cascade. J Neuroinflammation. 2011;8:129.

155. Villar-Cheda B, Valenzuela R, Rodriguez-Perez Al, Guerra MJ, LabandeiraGarcia JL. Aging-related changes in the nigral angiotensin system enhances proinflammatory and pro-oxidative markers and 6-OHDA-induced dopaminergic degeneration. Neurobiol Aging. 2012;33:204:e201-11.

156. Lee $S B$, Bae $I H$, Bae YS, Um HD. Link between mitochondria and NADPH oxidase 1 isozyme for the sustained production of reactive oxygen species and cell death. J Biol Chem. 2006:281:36228-35.

157. Pickrell AM, Youle RJ. The roles of PINK1, parkin, and mitochondrial fidelity in Parkinson's disease. Neuron. 2015:85:257-73.

158. Gandhi S, Wood-Kaczmar A, Yao Z, Plun-Favreau H, Deas E, Klupsch K, Downward J, et al. PINK1-associated Parkinson's disease is caused by neuronal vulnerability to calcium-induced cell death. Mol Cell. 2009;33:627-38.

159. Dikalov S. Cross talk between mitochondria and NADPH oxidases. Free Radic Biol Med. 2011;51:1289-301. 
160. Zinkevich NS, Gutterman DD. ROS-induced ROS release in vascular biology: redox-redox signaling. Am J Physiol Heart Circ Physiol. 2011;301:H647-53.

161. Calabresi P, Picconi B, Parnetti L, Di Filippo M. A convergent model for cognitive dysfunctions in Parkinson's disease: the critical dopamineacetylcholine synaptic balance. Lancet Neurol. 2006;5:974-983.

162. Gardoni F, Bellone C. Modulation of the glutamatergic transmission by dopamine: a focus on Parkinson, Huntington and addiction diseases. Front Cell Neurosci. 2015;9:25.

163. Kamsler A, Segal M. Paradoxical actions of hydrogen peroxide on long-term potentiation in transgenic superoxide dismutase-1 mice. J Neurosci. 2003;23: 10359-67.

164. Ahmed I, Bose SK, Pavese N, Ramlackhansingh A, Turkheimer F, Hotton G, Hammers A, et al. Glutamate NMDA receptor dysregulation in Parkinson's disease with dyskinesias. Brain. 2011;134:979-86.

165. Behrens MM, Ali SS, Dugan LL. Interleukin-6 mediates the increase in NADPH-oxidase in the ketamine model of schizophrenia. J Neurosci. 2008; 28:13957-66.

166. Ali SS, Young JW, Wallace CK, Gresack J, Jeste DV, Geyer MA, Dugan LL, et al. Initial evidence linking synaptic superoxide production with poor short-term memory in aged mice. Brain Res. 2011;1368:65-70.

167. Brennan AM, Suh SW, Won SJ, Narasimhan P, Kauppinen TM, Lee H, Edling $Y$, et al. NADPH oxidase is the primary source of superoxide induced by NMDA receptor activation. Nat Neurosci. 2009:12:857-63.

168. Sorce $S$, Schiavone S, Tucci $P$, Colaianna M, Jaquet V, Cuomo V, DuboisDauphin $\mathrm{M}$, et al. The NADPH oxidase NOX2 controls glutamate release: a novel mechanism involved in psychosis-like ketamine responses. J Neurosci. 2010;30:11317-25.

169. Patel M, Day BJ, Crapo JD, Fridovich I, McNamara JO. Requirement for superoxide in excitotoxic cell death. Neuron. 1996;16:345-55.

170. Brennan-Minnella AM, Shen Y, El-Benna J, Swanson RA. Phosphoinositide 3kinase couples NMDA receptors to superoxide release in excitotoxic neuronal death. Cell Death Dis. 2013:4:e580.

171. Mutez E, Nkiliza A, Belarbi K, de Broucker A, Vanbesien-Mailliot C, Bleuse S, Duflot $A$, et al. Involvement of the immune system, endocytosis and EIF2 signaling in both genetically determined and sporadic forms of Parkinson's disease. Neurobiol Dis. 2014;63:165-170.

172. Elstner M, Morris CM, Heim K, Bender A, Mehta D, Jaros E, Klopstock T, et al. Expression analysis of dopaminergic neurons in Parkinson's disease and aging links transcriptional dysregulation of energy metabolism to cell death. Acta Neuropathol. 2011:122:75-86.

173. Hu W, Tian H, Yue W, Li L, Li S, Gao C, Si L, et al. Rotenone induces apoptosis in human lung cancer cells by regulating autophagic flux. IUBMB Life. 2016;68:388-93.

174. Pan T, Rawal P, Wu Y, Xie W, Jankovic J, Le W. Rapamycin protects against rotenone-induced apoptosis through autophagy induction. Neuroscience. 2009;164:541-51.

175. Dadakhujaev S, Noh HS, Jung EJ, Cha JY, Baek SM, Ha JH, Kim DR. Autophagy protects the rotenone-induced cell death in alpha-synuclein overexpressing SH-SY5Y cells. Neurosci Lett. 2010;472:47-52.

176. Pal R, Palmieri M, Loehr JA, Li S, Abo-Zahrah R, Monroe TO, Thakur PB, et al. Src-dependent impairment of autophagy by oxidative stress in a mouse model of Duchenne muscular dystrophy. Nat Commun. 2014;5:4425

177. Pal R, Bajaj L, Sharma J, Palmieri M, Di Ronza A, Lotfi P, Chaudhury A, et al. NADPH oxidase promotes Parkinsonian phenotypes by impairing autophagic flux in an mTORC1-independent fashion in a cellular model of Parkinson's disease. Sci Rep. 2016;6:22866.

178. Sobhakumari A, Schickling BM, Love-Homan L, Raeburn A, Fletcher EV, Case AJ, Domann FE, et al. NOX4 mediates cytoprotective autophagy induced by the EGFR inhibitor erlotinib in head and neck cancer cells. Toxicol Appl Pharmacol. 2013;272:736-45

179. Sciarretta S, Zhai P, Shao D, Zablocki D, Nagarajan N, Terada LS, Volpe M, et al. Activation of $\mathrm{NADPH}$ oxidase 4 in the endoplasmic reticulum promotes cardiomyocyte autophagy and survival during energy stress through the protein kinase RNA-activated-like endoplasmic reticulum kinase/eukaryotic initiation factor 2alpha/activating transcription factor 4 pathway. Circ Res. 2013;113:1253-64.

180. Schapira AH. Targeting mitochondria for neuroprotection in Parkinson's disease. Antioxid Redox Signal. 2012;16:965-73.

181. Aldieri E, Riganti C, Polimeni M, Gazzano E, Lussiana C, Campia I, Ghigo D. Classical inhibitors of NOX NAD(P)H oxidases are not specific. Curr Drug Metab. 2008;9:686-96
182. Sedeek M, Callera G, Montezano A, Gutsol A, Heitz F, Szyndralewiez C, Page $P$, et al. Critical role of Nox4-based NADPH oxidase in glucose-induced oxidative stress in the kidney: implications in type 2 diabetic nephropathy. Am J Physiol Renal Physiol. 2010;299:F1348-58.

183. Laleu B, Gaggini F, Orchard M, Fioraso-Cartier L, Cagnon L, HoungninouMolango S, Gradia A, et al. First in class, potent, and orally bioavailable NADPH oxidase isoform 4 (Nox4) inhibitors for the treatment of idiopathic pulmonary fibrosis. J Med Chem. 2010;53:7715-30.

184. Aoyama T, Paik YH, Watanabe S, Laleu B, Gaggini F, Fioraso-Cartier L, Molango $S$, et al. Nicotinamide adenine dinucleotide phosphate oxidase in experimental liver fibrosis: GKT137831 as a novel potential therapeutic agent. Hepatology. 2012;56:2316-27.

185. Teixeira G, Szyndralewiez C, Molango S, Carnesecchi S, Heitz F, Wiesel P, Wood JM. Therapeutic potential of NADPH oxidase 1/4 inhibitors. Br J Pharmacol. 2017:174:1647-69.

186. Diebold BA, Smith SM, Li Y, Lambeth JD. NOX2 as a target for drug development: indications, possible complications, and progress. Antioxid Redox Signal. 2015;23:375-405

187. Touyz RM, Schiffrin EL. Reactive oxygen species in vascular biology: implications in hypertension. Histochem Cell Biol. 2004;122:339-52.

188. Wilcox CS. Oxidative stress and nitric oxide deficiency in the kidney: a critical link to hypertension? Am J Physiol Regul Integr Comp Physiol. 2005: 289:R913-35.

189. Sharma N, Kapoor M, Nehru B. Apocyanin, NADPH oxidase inhibitor prevents lipopolysaccharide induced alpha-synuclein aggregation and ameliorates motor function deficits in rats: possible role of biochemical and inflammatory alterations. Behav Brain Res. 2016;296:177-90.

190. Wang Q, Chu CH, Oyarzabal E, Jiang L, Chen SH, Wilson B, Qian L, et al. Subpicomolar diphenyleneiodonium inhibits microglial NADPH oxidase with high specificity and shows great potential as a therapeutic agent for neurodegenerative diseases. Glia. 2014:62;2034-43.

\section{Submit your next manuscript to BioMed Central and we will help you at every step:}

- We accept pre-submission inquiries

- Our selector tool helps you to find the most relevant journal

- We provide round the clock customer support

- Convenient online submission

- Thorough peer review

- Inclusion in PubMed and all major indexing services

- Maximum visibility for your research

Submit your manuscript at www.biomedcentral.com/submit
) Biomed Central 